\title{
Detection of Diverse
} $\mathrm{N}$-Acyl-Homoserine Lactones in Vibrio alginolyticus and Regulation of Biofilm Formation by $\mathrm{N}$-(3-Oxodecanoyl) Homoserine Lactone In vitro

\section{OPEN ACCESS}

Edited by:

Marcelino T. Suzuki,

Sorbonne Universities (UPMC) and

CNRS, France

Reviewed by:

Wim Vyverman,

Ghent University, Belgium

Haiwei Luo,

Chinese University of Hong Kong,

Hong Kong

*Correspondence:

Yinlin Ge

geyinlin@126.com

Lijun Zhou

hzzhoulj@126.com

${ }^{\dagger}$ These authors have contributed equally to this work

Specialty section

This article was submitted to

Aquatic Microbiology,

a section of the journal

Frontiers in Microbiology

Received: 26 December 2016

Accepted: 30 May 2017

Published: 16 June 2017

Citation:

Liu J, Fu K, Wang Y, Wu C, Li F, Shi L, Ge $Y$ and Zhou L (2017) Detection of Diverse N-Acyl-Homoserine Lactones in Vibrio alginolyticus and Regulation of Biofilm Formation by N-(3-Oxodecanoyl) Homoserine Lactone In vitro.

Front. Microbiol. 8:1097. doi: 10.3389/fmicb.2017.01097

\author{
Jianfei Liu ${ }^{1,2 \dagger}$, Kaifei $\mathrm{Fu}^{2 \dagger}$, Yuxiao Wang ${ }^{2}$, Chenglin $\mathrm{Wu}^{2}$, Fei $\mathrm{Li}^{2}$, Lei Shi ${ }^{3}$, Yinlin $\mathrm{Ge}^{1 *}$ and \\ Lijun $\mathrm{Zhou}^{2 *}$
}

${ }^{1}$ Department of Biochemistry and Molecular Biology, Medical College of Qingdao University, Qingdao, China, ${ }^{2}$ Central Laboratory, Navy General Hospital of PLA, Beijing, China, ${ }^{3}$ Institute of Food Safety and Nutrition, Jinan University,

Guangzhou, China

Quorum sensing (QS) is a cell-to-cell communication system based on the exchange of small intercellular signal molecules, such as N-Acyl homoserine lactones (AHLs), which act as cell-density mediators of QS gene expression, and are highly variable both in types and amounts in most Gram-negative Proteobacteria. Understanding the regulation of AHLs may contribute to the elucidation of cell density-dependent phenomena, such as biofilm formation. Vibrio alginolyticus is among the most frequently observed marine opportunistic Vibrio pathogens. However, AHL production of this species and its effects on biofilm formation remain to be understood. Here, our study reported the diverse $\mathrm{AHL}$ profiles of 47 marine-isolated $V$. alginolyticus strains and the effects of exogenous 3-oxo- $\mathrm{C}_{10}$ - $\mathrm{HSL}$ on biofilm formation under different temperature conditions $\left(16^{\circ} \mathrm{C}\right.$ and $\left.28^{\circ} \mathrm{C}\right)$. A total of 11 detected AHLs were produced by the isolates, of which $3-\mathrm{OH}-\mathrm{C}_{4}-\mathrm{HSL}$, 3-oxo- $\mathrm{C}_{10}-\mathrm{HSL}$ and 3-oxo- $\mathrm{C}_{14}-\mathrm{HSL}$ comprised the largest proportions. We also observed that moderate levels of exogenous $3-0 x 0-\mathrm{C}_{10}-\mathrm{HSL}$ (10 and $20 \mu \mathrm{M}$ ) could induce or enhance biofilm formation and alter its structure, while high levels (40 and $100 \mu \mathrm{M}$ ) did not significantly improve and even inhibited biofilm formation in $V$. alginolyticus. Further, regulation by exogenous $3-0 x 0-\mathrm{C}_{10}-\mathrm{HSL}$ was both concentration- and temperature-dependent in $V$. alginolyticus.

Keywords: $\mathrm{N}$-acyl homoserine lactones, quorum sensing, Vibrio alginolyticus, 3-oxo- $\mathrm{C}_{10}-\mathrm{HSL}$, biofilm formation, biofilm matrix, CLSM

\section{INTRODUCTION}

Quorum Sensing (QS) is an important communication system used by bacterial cells, which allows monitoring of cell density and regulation of functions within the population. This process depends on the production, secretion, accumulation and recognition of signaling autoinducers (AIs; Bassler, 1999). The initial regulation of QS provides a cascade of controls that propels the bacterial community to express an advantageous phenotype and ensure their survival (Williams et al., 2007; Hawver et al., 2016). Further studies revealed that QS could also receive feedback 
from its components, allowing the cells to adjust their regulation in real-time (Reuter et al., 2016). Efficiency in changing the bacterial phenotype controlled by QS during proliferation is a key factor to effectively coordinate the behavior of the entire bacterial population, such as the biofilm formation in response to hostile conditions, thus, enhancing the survival of Proteobacteria.

$\mathrm{N}$-acyl homoserine lactones (AHLs) are a typical group of small AI molecules that mediate the QS phenomenon in gramnegative Proteobacteria especially in responding to changes in the environment (Williams et al., 2007; Garcia-Aljaro et al., 2008). AHLs are amphiphilic chemical compounds that share the same structure including a hydrophilic homoserine lactone ring and a hydrophobic acyl side chain (O'Connor et al., 2015). The diversity of AHLs is based on the number of carbon atoms (4, $6,7,8,10,12,14,16$, or 18) on the acyl side chain and substituent (hydrogen, oxhydryl or carbonyl; Kumari et al., 2006) present on the 3rd carbon atom, which are also the basis for distinction and important in regulating specificity. As an essential part of the QS system, AHL molecules are synthesized by certain synthases (e.g., LuxI type synthases) and bind to transcripts (e.g., LuxR type regulators), followed by the binding of the AHL-receptor complex to DNA, initiating the downstream regulation of QScontrolled genes (Swift et al., 2001). The N-( $\beta$-ketocaproyl)homoserine lactone (3-oxo- $\mathrm{C}_{6}$-HSL) in Vibrio fischeri was the first AHL to be described (Eberhard et al., 1981), and subsequent studies have uncovered more AHLs produced by other Gramnegative Proteobacteria. These include N-butyryl-homoserine lactone ( $\mathrm{C}_{4}$-HSL), N-(3-hydroxybutyryl)-homoserine lactone (3$\mathrm{OH}-\mathrm{C}_{4}$-HSL), N-hexanoyl-homoserine lactone $\left(\mathrm{C}_{6}-\mathrm{HSL}\right), \mathrm{N}$ (3-oxodecanoyl)-homoserine lactone (3-oxo- $\mathrm{C}_{10}$-HSL), among others (Valiente et al., 2009; Wang et al., 2013; Tan W. S. et al., 2014; Jamuna and Ravishankar, 2016). AHLs are vital in the capacity of pathogenic Proteobacteria to invade surfaces, and are also involved in multiple physiological processes such as bioluminescence, production of virulence factors, biofilm formation and drug resistance (Horng et al., 2002; Lumjiaktase et al., 2006; Garcia-Aljaro et al., 2012) as summarized in Table 1.

Biofilm formation is an important characteristic of bacterial communities that enhances invasion leading to infection, drug resistance, and pathogenicity (Soto et al., 2007; Naves et al., 2008). Thus, it is critical to elucidate the underlying mechanisms involved in QS system to further understand biofilm formation. Recent studies showed that QS controls the transformation of bacteria from being free-living or planktonic to colonial or biofilm-forming state, and further regulates and coordinates the behavior of the entire community, allowing synchronized response to environmental challenges to enhance viability (Mireille Aye et al., 2015; Okutsu et al., 2015). QS further regulates the construction of biofilm matrix and speeds up the process of biofilm formation (Tseng et al., 2016). It could also indirectly upregulate biofilm thickness by increasing bacterial motility (Yang et al., 2014). QS also increases dispersal of detached bacteria from the matured biofilm to trigger a new developmental cycle of biofilm formation (Emerenini et al., 2015).

Increasing reports of characterized AHLs in different bacterial species have provided valuable insights into how
AHLs regulate bacterial biofilm formation. For example, Vinoj et al. (2014) showed that AHLs produced by Vibrio parahaemolyticus could regulate formation of biofilm and enhancement of colonization. Meanwhile, N-octanoylhomoserine lactone $\left(\mathrm{C}_{8}-\mathrm{HSL}\right)$ and 3-oxo- $\mathrm{C}_{12}$ - $\mathrm{HSL}$ were also found to be responsible for biofilm formation in Pseudomonas aeruginosa and Aeromonas hydrophila, respectively (Abbas et al., 2007; Khajanchi et al., 2009). N-dodecanoyl-homoserine lactone $\left(\mathrm{C}_{12}\right.$-HSL) positively regulated biofilm formation in Salmonella enteritidis (Campos-Galvao et al., 2016). Huang et al. (2009) further showed that AHLs changed in the course of biofilm formation, first being dominated by short sidechain AHLs followed by an increase in long side-chain AHLs, indicating a feedback regulation mechanism. However, bacterial growth, QS molecules and biofilm formation could also be inhibited by key abiotic variables, such as temperature and composition of the culture medium (Yates et al., 2002; Sheng et al., 2013; Turner et al., 2014; Lamas et al., 2016). Hare et al. (1981) for example, observed that the production of extracellular collagenase and alkaline protease needed for biofilm formation were inhibited when the temperature increased from $30^{\circ} \mathrm{C}$ to $37^{\circ} \mathrm{C}$.

Vibrio alginolyticus is one of the most abundant aquatic pathogenic Vibrio (Mechri et al., 2013), proliferating well in a wide range of environments including offshore and coastal areas, rivers, sediments, and saline waters (Narracci et al., 2014). It also has a wide geographic distribution, with recorded presence in several marine environments, such as east (He et al., 2016) and south China Sea (Wu et al., 2016), west Korea sea (Kang et al., 2016), and Indian Ocean (Gauzere et al., 2016). This environmental opportunistic pathogen has long been a threat to fishing industry, and has been reported to cause human diseases worldwide. Human $V$. alginolyticus infections include several acute and even deadly conditions like diarrhea, septicemia, and the inflammation of multiple tissues (Caccamese and Rastegar, 1999; Sganga et al., 2009; Gauzere et al., 2016). So far, there are relatively fewer studies on biofilms of $V$. alginolyticus, and mostly concentrated on virulence-related genes in correlation with biofilm formation. Despite evidence that biofilm forming $V$. alginolyticus strains activate stronger immune response in juvenile tiger shrimp than planktonic strains, and that the former were superior to the latter in stimulating non-specific immune response (Sharma et al., 2010), studies on biofilm effects in human infection remain limited.

Recent studies on genetic basis of QS regulation in $V$. alginolyticus mostly focused on the possible effects of LuxR type genes (i.e., virulence related gene $\mathrm{Hfq}$ ) and QS signaling transcriptional regulators, e.g., motility regulated extracellular protein Pep and the colony phenotype intermediated protein valR (Chang et al., 2010; Cao et al., 2011; Liu et al., 2011). Although the LuxR type homolog of $V$. alginolyticus could induce the alteration of colony phenotype and regulate flagellar biosynthesis relating to its biofilm formation (Chang et al., 2010), the direct QS signaling control on V. alginolyticus biofilm formation has not yet been well explored, which might be partly attributed to the less understood production of AHLs in $V$. alginolyticus. To our knowledge, no detailed profiling of 
TABLE 1 | Biological and physiological functions of AHL molecules.

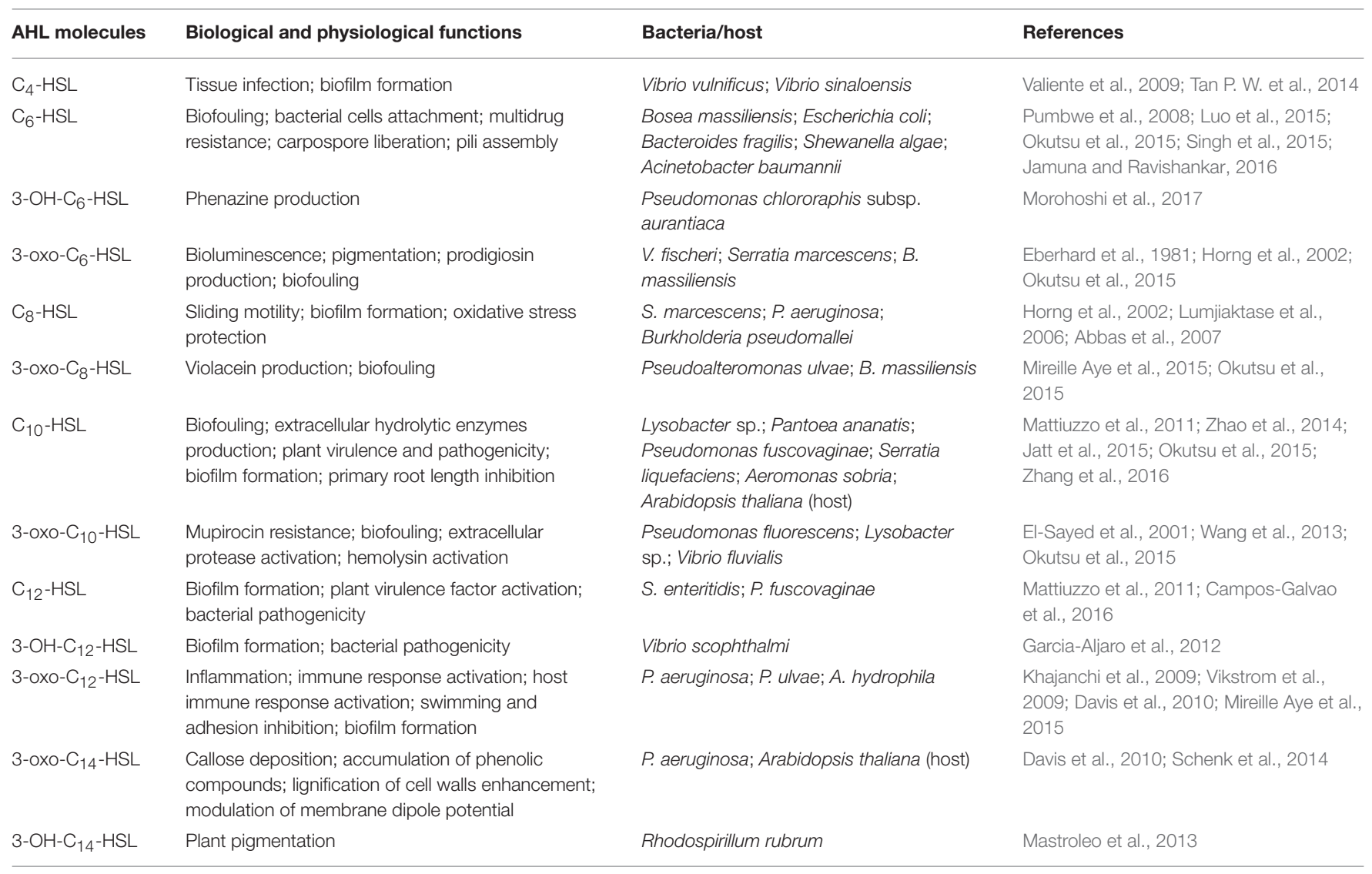

AHL signals and their effects on biofilm formation have yet been carried out in $V$. alginolyticus. Therefore, the elucidation of AHL profiles in $V$. alginolyticus and their relationship with biofilm formation is of interest to the control of $V$. alginolyticus infections.

To fill in some of these knowledge gaps, with the aim of gaining further understanding of mechanisms involved in QS, our study focused on the identification of different AHLs in $V$. alginolyticus strains, which were also used to investigate the detailed relationship between biofilm formation and AHLs under different temperature conditions. The acquired knowledge provides interesting perspectives regarding the roles of QS signaling molecules in aquatic pathogens.

\section{MATERIALS AND METHODS}

\section{Bacterial Isolation and Growth Conditions}

A total of 47 strains of marine $V$. alginolyticus (hereafter referred to as strains $\mathrm{N}^{\circ} 01-\mathrm{N}^{\circ} 47$ ) were isolated from Bohai, China and cultured in $2216 \mathrm{E}$ broth (BD Biosciences, USA) at $28^{\circ} \mathrm{C}$ and $180 \mathrm{rpm}$ of shaking. Biochemical identification was performed using the VITEK 2 compact system (Biomérieux, France), following the manufacturer's instructions. For the cross-feeding assay, the transformed biosensor strain Chromobacterium violaceum CV026 was used for short side-chain AHLs detection (C 4 -HSL-C 8 -HSL; McClean et al., 1997; Ravn et al., 2001), and was cultured in Luria Bertani (LB) broth with $40 \mu \mathrm{g} / \mathrm{mL}$ kanamycin (Sigma, USA) at $28^{\circ} \mathrm{C}$ and $180 \mathrm{rpm}$ of shaking for 16 h. The transformed biosensor strain Agrobacterium tumefaciens KYC55 (JZA1-1) was used for long side-chain AHLs (C $\mathrm{C}_{8}$-HSL$\mathrm{C}_{14}$-HSL) detection (Zhu and Mekalanos, 2003; Golberg et al., 2011), and was cultured in LB broth with $1 \mu \mathrm{g} / \mathrm{mL}$ tetracycline, $100 \mu \mathrm{g} / \mathrm{mL}$ spectinomycin and $100 \mu \mathrm{g} / \mathrm{mL}$ gentamycin (Sigma, USA) at $28^{\circ} \mathrm{C}$ and $180 \mathrm{rpm}$ of shaking for $16 \mathrm{~h}$. The positive control strains Erwinia carotovora GS101 (Chhabra et al., 1993) and P. aeruginosa PAO1 (Tateda et al., 2003) were cultured in LB broth for $24 \mathrm{~h}$ and $16 \mathrm{~h}$, respectively. All bacterial strains used in this study were listed in Supplementary Table 1.

\section{AHL Detection of $V$. alginolyticus Cross-Feeding Assay for AHL Production}

To determine the range of AHLs produced by strains $\mathrm{N}^{\circ} 01$ $\mathrm{N}^{\circ} 47$, the bacterial suspension was cross-fed with 2 biosensor strains (C. violaceum CV026 and A. tumefaciens KYC55) following the methods reported by Han-Jen et al. (2013) with modifications. Briefly, strains were cultured for $36 \mathrm{~h}$ and pelleted by centrifugation at $10,000 \mathrm{rpm}$ for $15 \mathrm{~min}$. Bacterial suspension was adjusted to a concentration of approximately $5 \times 10^{6}$ Colony Forming Units per milliliter $\left(\mathrm{CFU} / \mathrm{mL}\right.$; $\left.\mathrm{OD}_{570}=0.03\right)$, incubated with the reporter strains for $36 \mathrm{~h}$ at $28^{\circ} \mathrm{C}$. Before using A. tumefaciens KYC55 as the reporter strain, a new layer of 5-bromo-4-chloro-3-indolyl- $\beta$-D-galactoside (X-Gal, Amresco, USA) was added on the agar plate. 


\section{AHLs Profiling through High-Performance Liquid Chromatography Tandem Mass Spectrometry (HPLC-MS/MS) Assay}

The HPLC-MS/MS method was used to quantify the AHLs produced by all $V$. alginolyticus strains $\left(\mathrm{N}^{\circ} 01-\mathrm{N}^{\circ} 47\right)$. The 47 strains were adjusted to approximately $3 \times 10^{5} \mathrm{CFU} / \mathrm{mL}$ and were cultured for $36 \mathrm{~h}$. After incubation, each culture was centrifuged at $10,000 \mathrm{rpm}$ for $10 \mathrm{~min}$ and AHLs in supernatants were extracted with ethyl acetate with $0.1 \%(\mathrm{v} / \mathrm{v})$ formic acid. Extracts were freeze-dried using an ALPHA 1-2LD plus lyophiliser (CHRIST, Germany) as previously described in Tan W. S. et al. (2014). The extract was resuspended in $80 \mu \mathrm{L}$ of $99.9 \%$ HPLC-grade methanol (Thermo Fisher, USA) and was analyzed by HPLC-MS/MS.

The Prominence UFLC-XR (SHIMADZU, Japan) system was utilized for HPLC analysis with a Symmetry $\mathrm{C}_{18}$ reverse-phase column $(3.5 \mu \mathrm{m}, 2.1 \times 100 \mathrm{~mm}$; Waters, USA). Subsequently, MS analysis was performed on a Qtrap 5500 (AB SCIEX, USA) system using MRM mode with positive ion scanning. $\mathrm{C}_{4}$-HSL, N-(3-hydroxybutyryl)homoserine lactone (3-OH- $\left.\mathrm{C}_{4}-\mathrm{HSL}\right), \mathrm{C}_{6}-\mathrm{HSL}, 3-$ oxo- $_{6}-\mathrm{HSL}$, $\mathrm{C}_{8}$-HSL, N-(3-hydroxyoctanoyl)-homoserine lactone (3$\mathrm{OH}-\mathrm{C}_{8}$-HSL), $\mathrm{N}$-(3-oxooctanoyl)-homoserine lactone (3-oxo- $\mathrm{C}_{8}$-HSL), N-decanoyl-homoserine lactone ( $\mathrm{C}_{10}$-HSL), 3-oxo-C 10 -HSL, $\quad \mathrm{C}_{12}$-HSL, $\mathrm{N}$-(3-hydroxydodecanoyl)homoserine lactone (3-OH- $\mathrm{C}_{12}$-HSL), 3-oxo- $\mathrm{C}_{12}$-HSL, $\mathrm{N}$-(3-hydroxytetradecanoyl)-homoserine lactone (3-OH$\mathrm{C}_{14}$-HSL), and $\mathrm{N}$-(3-oxotetradecanoyl)-homoserine lactone (3-oxo- $\mathrm{C}_{14}$-HSL) were selected as the standards purchased from Sigma (USA). Two mmol/L ammonium acetate and $0.1 \%$ $(\mathrm{v} / \mathrm{v})$ formic acid were diluted in water as mobile phase A or in methanol as mobile phase $B$. The flow rate $(0.2 \mathrm{~mL} / \mathrm{min})$, analysis time (40 $\mathrm{min} / \mathrm{sample}$ ), and mobile gradient profile were optimized (Supplementary Table 2), and $20 \mu \mathrm{L}$ of each sample was analyzed. The following conditions were used for MS: electron spray ionization (ESI) was set at $4.5 \mathrm{kV}$, the curtain gas (CUR) at 20 Psi, collision gas (CAD) at medium, temperature (TEM) at $650^{\circ} \mathrm{C}$, ion source gas 1 (GS1) at $40 \mathrm{Psi}$, and ion source gas 2 (GS2) was set at 45 Psi. Also, optimum quantitative ion pairs $(\mathrm{m} / \mathrm{z})$ were determined under Multiple Reaction Monitoring (MRM) mode following McLafferty and Turecek (1993) rearrangement (Supplementary Table 3), with a linear correlation coefficient greater than 0.99 for each standard compound (Supplementary Table 4). Standard curves were drawn with the peak area on the $Y$-axis and the corresponding concentration on the $X$-axis from which the slope was calculated.

\section{Detection of V. alginolyticus Biofilms \\ Biofilm Formation}

The 47 strains (adjusted to $3 \times 10^{5} \mathrm{CFU} / \mathrm{mL}$ ) were incubated in 96-well polystyrene microplates (Corning, USA) at $28^{\circ} \mathrm{C}$ for $36 \mathrm{~h}$ from which biofilm formation was monitored. A semi-quantitative adhesion test modified from Stepanovic et al. (2000) was used. The CFU of suspended cultures were counted. The microplates were first rinsed with phosphatebuffered saline (PBS) solution and fixed with Bouin's fluid
(LEAGENE, China) for $20 \mathrm{~min}$, and then stained with crystal violet $(0.1 \%$, w/v solution; LEAGENE, China) for $30 \mathrm{~min}$, after which the excess crystal violet was washed off. The biofilms were dissolved in 95\% (v/v) ethanol and quantified at $\mathrm{OD}_{570}$ with a microplate reader (Model 680, BIO-RAD, USA). The standardized biofilm (BF) was calculated using the following formula: Standardized $\mathrm{OD}_{570 \text {, sample }}=\left(\right.$ original $\mathrm{OD}_{570 \text {, sample }}-$ $\left.\left.\mathrm{OD}_{570 \text {, control }}\right) / \log _{\mathrm{CFU} / \mathrm{mL}}\right)$.

Effect of temperature on biofilm formation was then investigated by subjecting the strains to a gradient of temperature. Temperature regimes used were based on those previously described by De Oliveira et al. (2014) and Miller et al. (2016). Specifically, 3 temperatures (16, 28, and $40^{\circ} \mathrm{C}$ ) were selected, hereafter referred to as low, moderate and high temperature conditions, respectively. Strain $\mathrm{N}^{\circ} 24$ (no 3-oxo- $\mathrm{C}_{10}$-HSL production and weak biofilm formation) and strain $\mathrm{N}^{\circ} 40$ (high level of 3-oxo- $\mathrm{C}_{10}$-HSL production and strong biofilm formation) were selected from the 47 strains for this particular part of the study. Cultures were adjusted to $3 \times 10^{5}$ $\mathrm{CFU} / \mathrm{mL}$ before being used.

To explore the effects of exogenous AHLs, specifically 3oxo- $\mathrm{C}_{10}$-HSL, on biofilm formation under different temperature conditions, strains $\mathrm{N}^{\circ} 24$ and $\mathrm{N}^{\circ} 40$ were separately supplemented with exogenous 3-oxo- $\mathrm{C}_{10}$-HSL at final concentrations of $1,2,5$, $10,20,40$, or $100 \mu \mathrm{mol} / \mathrm{L}$. For biofilm formation detection, 200 $\mu \mathrm{L}$ of 3 -oxo- $\mathrm{C}_{10}$-HSL treated strains were incubated in 96-well polystyrene microplates at $16^{\circ} \mathrm{C}$ or $28^{\circ} \mathrm{C}$ for $36 \mathrm{~h}$, and a culture prepared with DMSO (AppliChem, Germany) was used as the negative control. Finally, $1 \mathrm{~mL}$ of these cultures were incubated in a two-chamber cell imaging cover glass system (Eppendorf, Germany) while inclined to approximately $45^{\circ}$ to form a clear liquid-air interface, and was placed in a moist sterile incubation box for $36 \mathrm{~h}$ at $16^{\circ} \mathrm{C}$ or $28^{\circ} \mathrm{C}$ before being used for confocal laser scanning microscopy (CLSM) imaging. All treatments and assays were performed in triplicates.

\section{Fluorescence Labeling Microscopy (FLM) Assay}

Strains $\mathrm{N}^{\circ} 24$ and $\mathrm{N}^{\circ} 40$ were incubated in a 4 -well glass LabTek ${ }^{\circledR}$ II Chamber Slide System (NUNC, Denmark) while inclined at approximately $45^{\circ}$ to form a clear liquid-air interface, and placed in a moist sterile incubation box. The FLM assay was performed in the same cultures after $12,24,36,48,60,72$, $84,96,108$, and $120 \mathrm{~h}$ incubation period. Treatments for each strain were in triplicates. The wells were rinsed with PBS and fixed with $4 \%$ paraformaldehyde (LEAGENE, China) for 30 min. Then, the wells were labeled by FITC-ConA (Sigma, USA) for exopolysaccharides (EPS) and propidium iodide (PI; Sigma, USA) for bacterial nucleic acid, before rinsed finally with PBS. The slide was sealed with antifade mounting medium (Beyotime, China).

The pictures were taken with a Nikon ECLIPSE Ti-S Inverted Fluorescence Microscope (Nikon, Japan) equipped with $33 \mathrm{~mm}$ ND4/ND8 filters employing green filter detecting PI fluorescence (500-550/615 nm excitation/emission wavelengths) and blue filter to detect FITC fluorescence (400-490/525 nm 
excitation/emission wavelengths). The pictures were processed with NIS-Elements BR 3.0 software (Nikon, Japan).

\section{CLSM Assay of the Biofilm Matrix}

The biofilms were treated in the same manner as described in Section CLSM Assay of the Biofilm Matrix. Z-scans of the images were taken using LSM710 3-channel Zeiss confocal laser scanning microscope (Zeiss, Germany) equipped with TwinGate main beamsplitter employing 543/576-718 nm and 488/493-542 $\mathrm{nm}$ excitation/emission wavelengths. Scans were processed and reconstructed into 3D images using Zen v. 2.3 (Zeiss, Germany).

Five specific morphological traits were used as indices of biofilm structure as obtained from CLSM images, namely biomass, average and maximum thickness, roughness coefficient, and microcolonies at the substrate (Derlon et al., 2010), which were quantified and analyzed using the COMSTAT 2.1 software following Heydorn et al. (2000) and Vorregaard (2008).

Analysis of variance (ANOVA) and detection of significant differences (Dunnett's test) were carried out using the standardized OD $_{570}$ data in SPSS 19 (IBM Statistics, USA). All $P$-values were two-tailed, and the threshold for statistical significance was set at 0.05 . All results were presented as the mean values \pm standard deviations (SD) for all independent experiments in each group.

\section{RESULTS}

\section{AHL Profiling of $V$. alginolyticus}

Cross-feeding results showed that no bacterial suspension induced visible violacein production in C. violaceum CV026, indicating a lack of short side-chain AHL production by the tested $V$. alginolyticus strains. However, 43 out of the 47 strain suspensions (Figure 1) showed distinct blue color change in $A$. tumefaciens KYC55 with varying color intensities. In addition, traces of diffusing blue color on reporter strain was observed next to strain $\mathrm{N}^{\circ} 25$, which could indicate a strong long sidechain AHL production by adjacent strain $\mathrm{N}^{\circ} 27$. The bioassay results confirmed that most of the $V$. alginolyticus strains we tested produced long side-chain AHLs.

HPLC-MS/MS results further showed that the $V$. alginolyticus strains produced a total of 11 different AHLs, with each strain producing more than 6 AHL types. Table 2 lists all the detailed information about the detected AHLs and

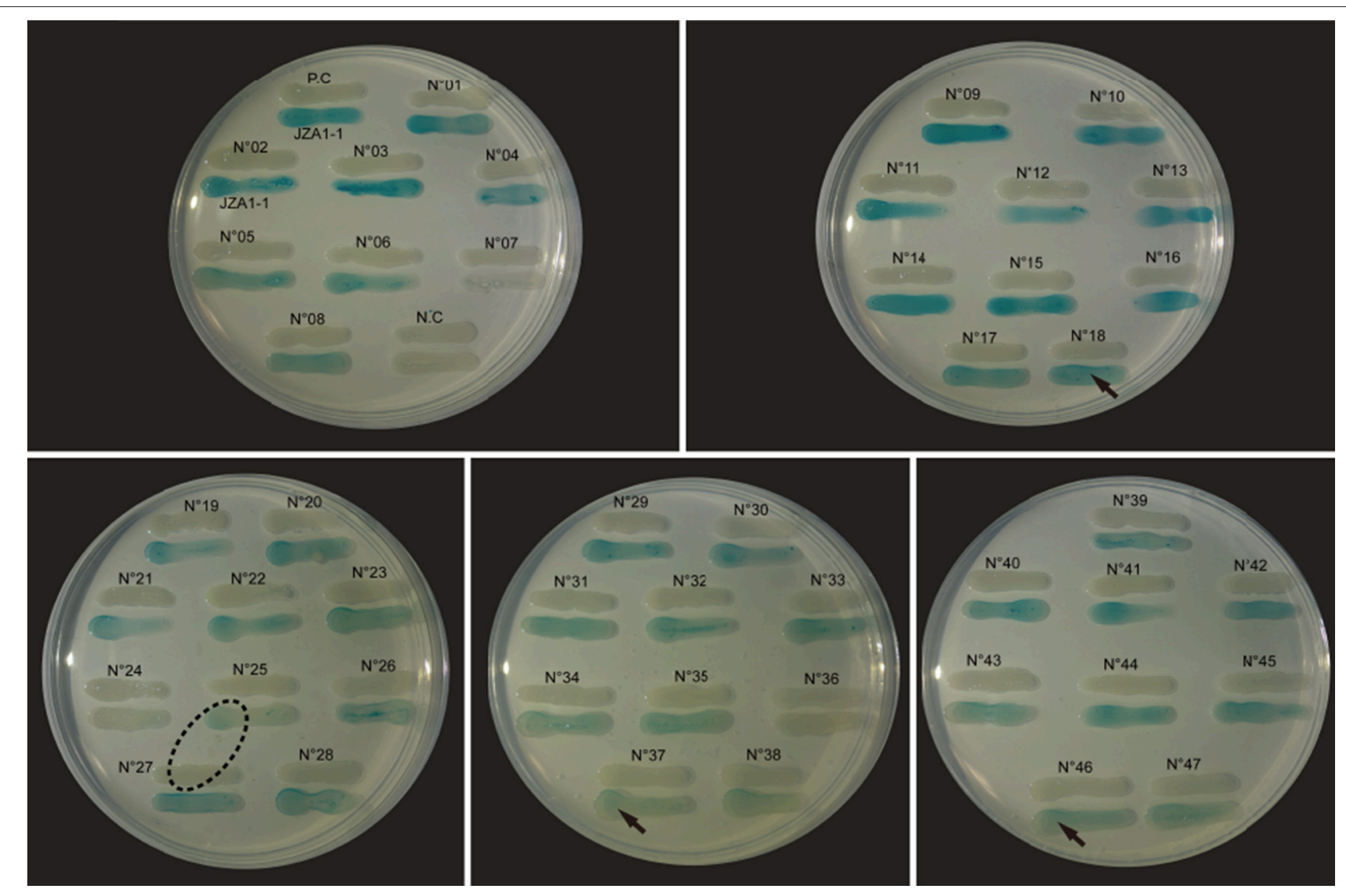

FIGURE 1 | Detection of long side-chain AHL production in V. alginolyticus. Strain suspensions cross fed with biosensor A. tumefaciens KYC55. The "JZA1-1" represents biosensor A. tumefaciens KYC55; the "P.C" (positive control) represents P. aeruginosa PAO1; the "N.C" (negative control) represents A. tumefaciens KYC55; the "arrow" symbol represents the visible color change induced from the proximal end to the distal end of the inducer; the "dashed oval" symbol represents the surface diffusion of the color change from the adjacent inducer. 
concentration classification of 47 strains, the results showed that the concentrations of short side-chain AHLs were all very low except for $3-\mathrm{OH}-\mathrm{C}_{4}-\mathrm{HSL}$, while those of the long sidechain AHLs were in a large scale and varied in between strains. The AHLs 3-oxo- $\mathrm{C}_{10}$-HSL, 3-OH- $\mathrm{C}_{4}$-HSL, and 3-oxo- $\mathrm{C}_{14}$-HSL were the most dominant and were produced by all the tested strains except for strain $\mathrm{N}^{\circ} 24$ (no 3-oxo- $\mathrm{C}_{10}$-HSL production). $\mathrm{C}_{6}$-HSL was detected only in trace concentrations and only produced by strain $\mathrm{N}^{\circ} 03$. Lastly, 3 AHLs including $\mathrm{C}_{8}$-HSL, 3oxo- $\mathrm{C}_{8}$ - HSL and $3-\mathrm{OH}-\mathrm{C}_{14}$-HSL were not detected in all tested strains.

\section{Biofilms Formed by V. alginolyticus Strains}

Semi-quantitative adhesion test revealed that the 47 strains exhibited diverse biofilm-forming abilities after $36 \mathrm{hrs}$ of incubation (Figure 2). We further grouped the 47 strains based on their level of biofilm formation namely, no biofilm (12 strains; standardized biofilm: $<0.01$ ), weak biofilm producers (32 strains, standardized biofilm: 0.01-0.05), moderate producers (2 strains; standardized biofilm: 0.05-0.15), and a strain that had the highest biofilm production (standardized biofilm: $>0.15$ ).

Furthermore, among these strains two showed remarkably contrasting responses relative to 3 -oxo- $\mathrm{C}_{10}$ - $\mathrm{HSL}$ production (Table 2) and biofilm formation (Figure 2). Specifically, strain $\mathrm{N}^{\circ} 24$ produced 3-oxo- $\mathrm{C}_{10}$-HSL with weak biofilm formation, while strain $\mathrm{N}^{\circ} 40$ produced high levels of 3 -oxo- $\mathrm{C}_{10}$-HSL accompanied by having the strongest biofilm formation. Thus, the contrasting characteristics of biofilm formation of these 2 strains could suggest the distinct strain specificity in the effects of exogenous 3-oxo- $\mathrm{C}_{10}$-HSL.

During culturing from 12 to $120 \mathrm{~h}$, strain $\mathrm{N}^{\circ} 24$ did not exhibit any bacterial cell adhesion, while strain $\mathrm{N}^{\circ} 40$ generated a compact biofilm matrix with attached bacterial cells (Figure 3A). In addition, the solid biofilm structures of strain $\mathrm{N}^{\circ} 40$ became visible after $12 \mathrm{~h}$, reaching a maximum in biovolume in between 60 and $72 \mathrm{~h}$, followed by a collapse beginning at $84 \mathrm{~h}$. Moreover, the density of adhered bacterial cells reached highest at the liquid-air interface, where the biofilm was thought to be constructed in sheets. The structure gradually changed into a cross-linked network away from the interface, where the bacterial cells continued to grow and aggregated (Figure 3B).

\section{Effects of Exogenous 3-oxo- $\mathrm{C}_{10}-\mathrm{HSL}$ on Biofilm Formation \\ Biofilm Formation under Different Temperatures}

As shown in Figure 4, biofilm formation of strain $\mathrm{N}^{\circ} 24$ maintained very weak structure (standardized biofilm: 0.01-0.05) at $16^{\circ} \mathrm{C}$ and $28^{\circ} \mathrm{C}$, and further decreased at $40^{\circ} \mathrm{C}$ (standardized biofilm: <0.01). Biofilm formation of strain $\mathrm{N}^{\circ} 40$ significantly increased at $16^{\circ} \mathrm{C}$ compared to that at $28^{\circ} \mathrm{C}$ but was significantly weaker (standardized biofilm: $<0.01$ ) at $40^{\circ} \mathrm{C}$. These indicate that to some extent, high temperature could inhibit $V$. alginolyticus biofilm formation.

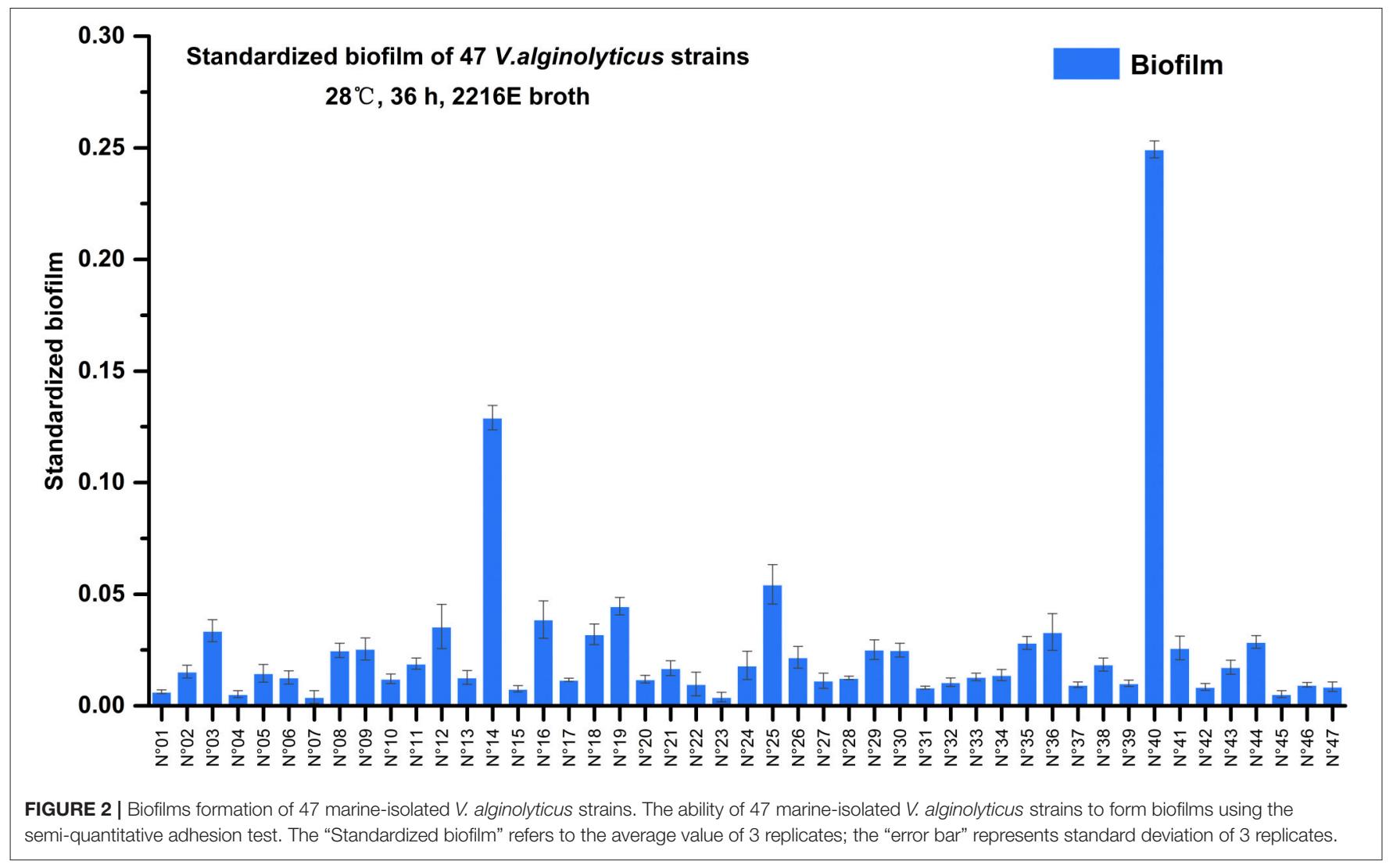




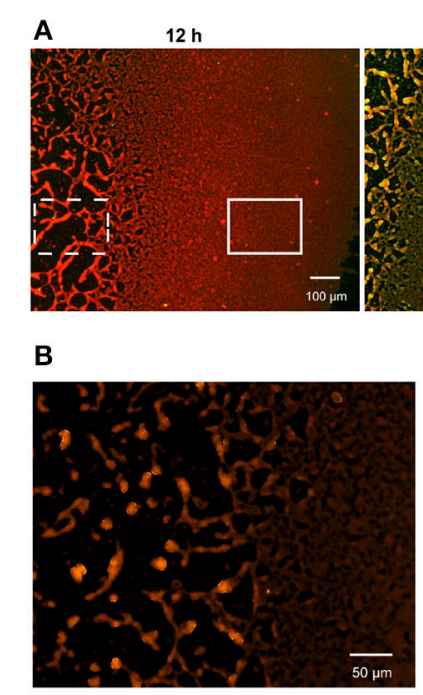

PI
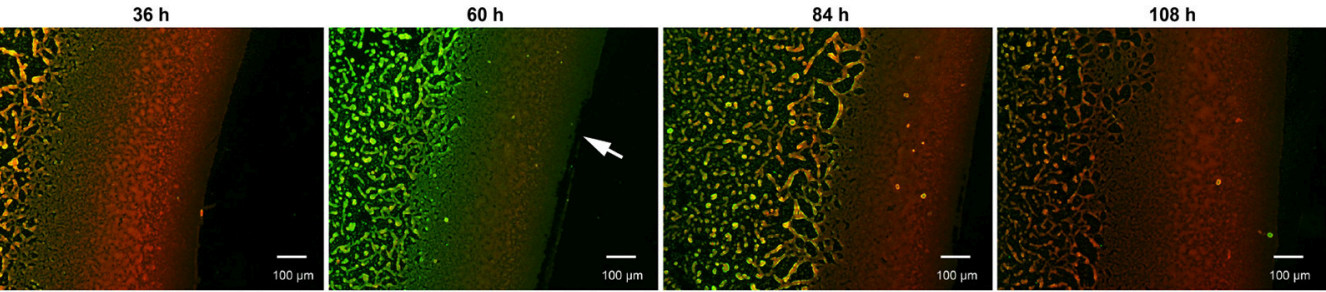

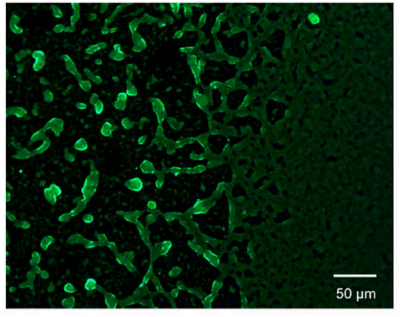

FITC-ConA

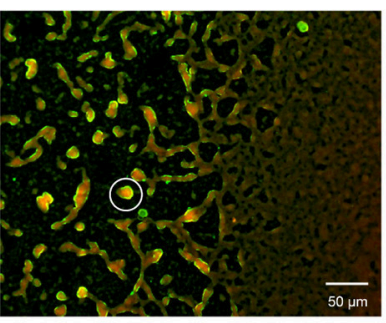

Merged

FIGURE 3 | Determination of biofilm formation in V. alginolyticus by FLM. (A) Representative images of biofilm formed by strain $\mathrm{N}^{\circ} 40$. Bar: 100 $\mu$ m. (B) The matrix and bacterial cells in the biofilm formed by strain $N^{\circ} 40$. Bar: $50 \mu \mathrm{m}$. The "Solid rectangular box" symbol represents biofilm matrix constructed in sheets; the "dotted rectangular box" symbol represents biofilm matrix in a network; the "solid circle" symbol represents a bacterial community formed by bacterial cells and matrix; the "arrow" symbol represents the liquid-air interface.

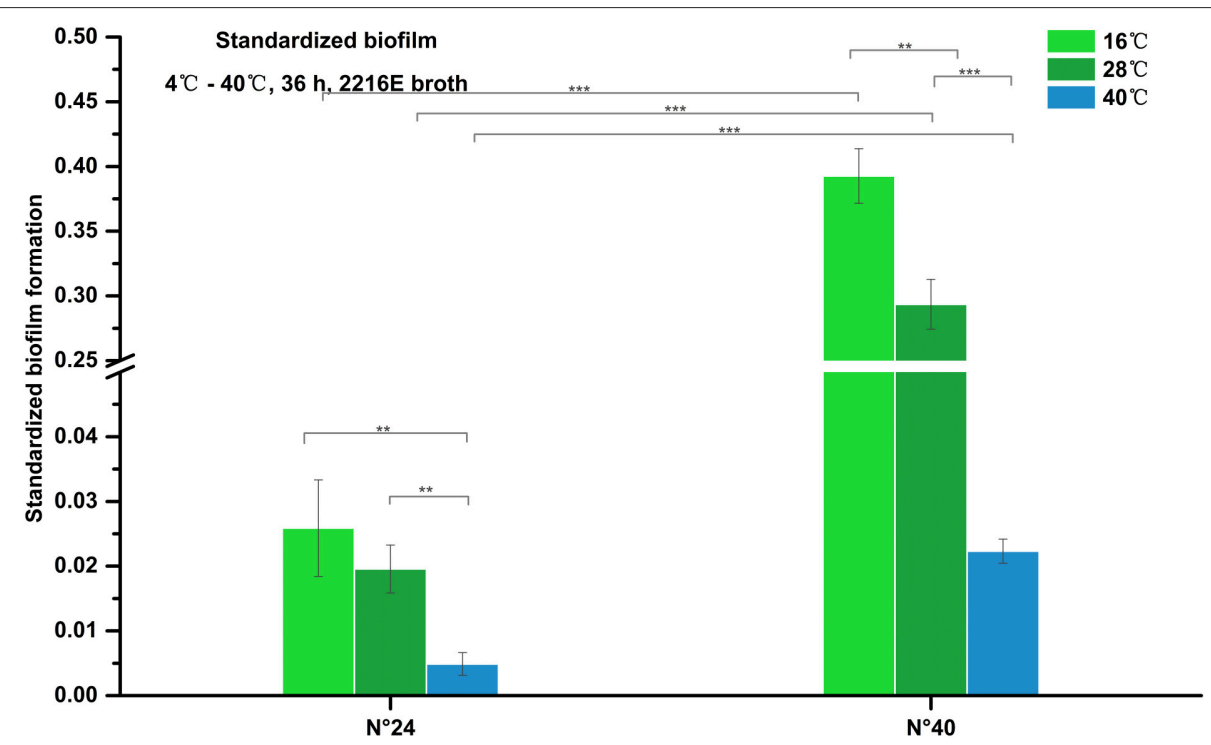

FIGURE 4 | Biofilm formation of $V$. alginolyticus at different temperatures. Results of the semi-quantitative test of biofilm formation of strains $\mathrm{N}^{\circ} 24$ and $\mathrm{N}^{\circ} 40$ cultured for $36 \mathrm{~h}$ at 16,28 , and $40^{\circ} \mathrm{C}$. The "Standardized biofilm" corresponds to the mean of 3 replicates with error bars for standard deviation; ${ }^{\star \star} P<0.01$; ${ }^{\star \star \star} P<0.001$.

\section{Effects of 3-oxo- $\mathrm{C}_{10}-\mathrm{HSL}$ on Biofilm Formation at $16^{\circ} \mathrm{C}$}

As shown in Figure $\mathbf{5 A}$, the biofilms of strain $\mathrm{N}^{\circ} 24$ significantly increased when supplemented with 2,5 , 10, and $20 \mu \mathrm{mol} / \mathrm{L} 3$-oxo- $\mathrm{C}_{10}$-HSL. On the other hand, biofilm formation of strain $\mathrm{N}^{\circ} 40$ significantly decreased when supplemented with 40 and $100 \mu \mathrm{mol} / \mathrm{L}$ 3-oxo$\mathrm{C}_{10}$-HSL, but the other concentrations had no significant effects.
As shown in Figure 5B, strain $\mathrm{N}^{\circ} 24$ formed a spotted biofilm in the negative control group but formed a sheetlike biofilm in groups supplemented with 10 and $20 \mu \mathrm{mol} / \mathrm{L}$ 3-oxo- $\mathrm{C}_{10}$-HSL. Biofilms of the $10 \mu \mathrm{mol} / \mathrm{L} 3$-oxo- $\mathrm{C}_{10}$-HSL treated group were more homogeneous and thinner than the ridge-like biofilms of $20 \mu \mathrm{mol} / \mathrm{L} 3$-oxo- $\mathrm{C}_{10}$-HSL treated group. As shown in Figure $5 \mathrm{C}$, strain $\mathrm{N}^{\circ} 40$ in the negative control group formed a thick but non-homogeneous biofilm, with bacterial cells covering the bottom of the matrix. However, 
A

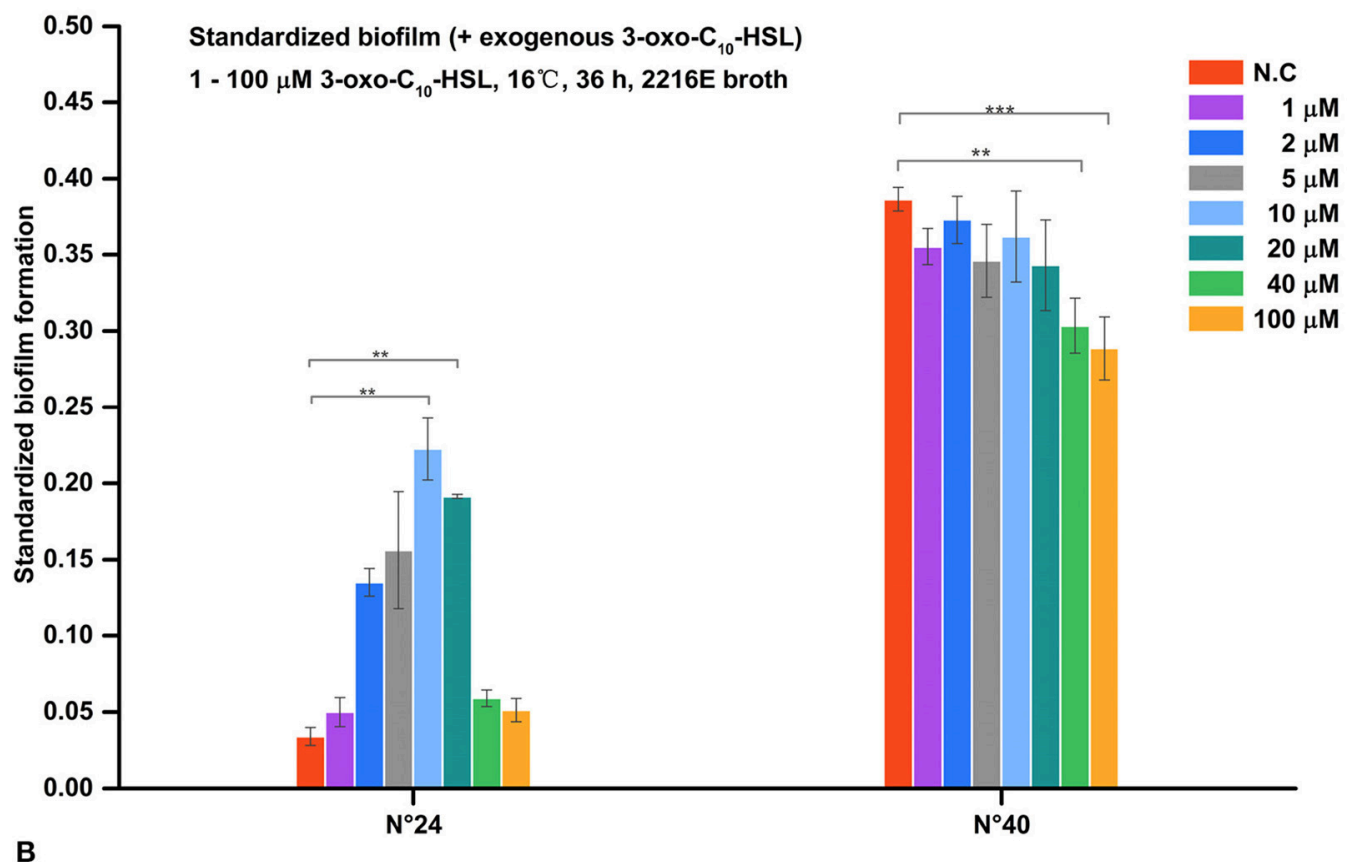

B

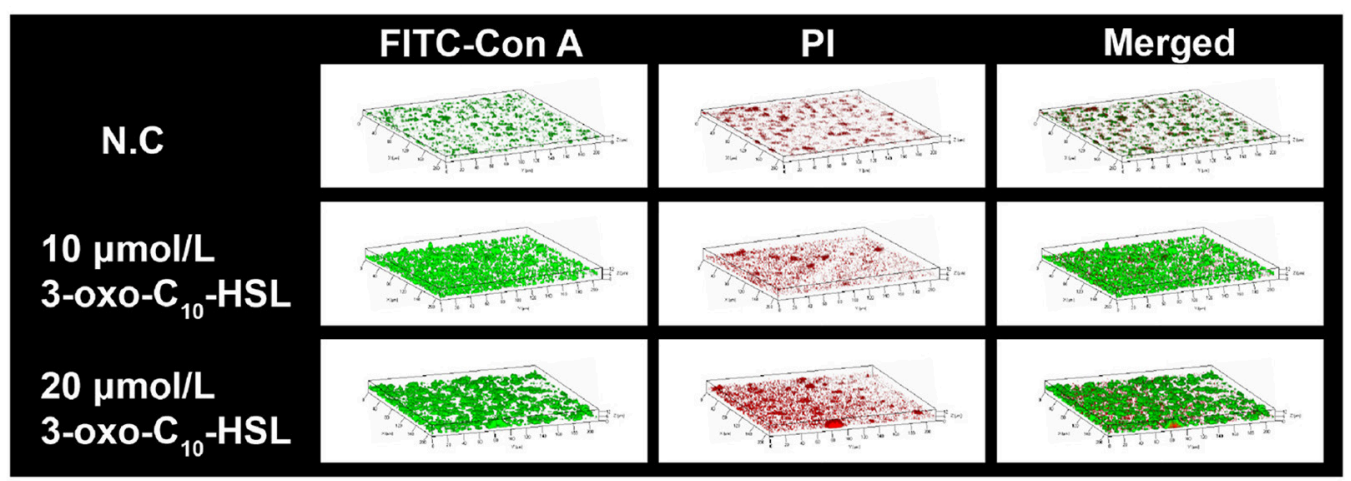

C

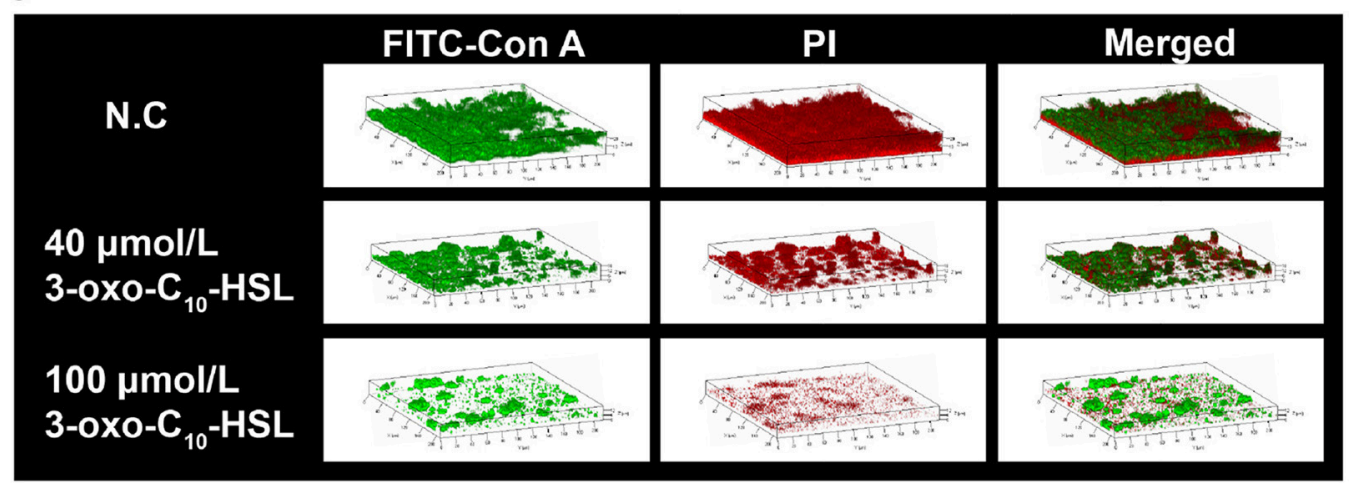

FIGURE 5 | Biofilm formation of $V$. alginolyticus upon supplementation with exogenous 3-oxo- $\mathrm{C}_{10}-\mathrm{HSL}$ at $16^{\circ} \mathrm{C}$. (A) Quantification of biofilms formed by strains $\mathrm{N}^{\circ} 24$ and $\mathrm{N}^{\circ} 40$ cultured for $36 \mathrm{~h}$ at $16^{\circ} \mathrm{C}$ using the semi-quantitative adhesion test. (B) Representative 3D-reconstructed biofilm structure of strain $\mathrm{N}^{\circ} 24 \mathrm{using} C \mathrm{CSM}$. (C) Representative 3D-reconstructed biofilm structure of strain N ${ }^{\circ} 40$ using CLSM. The "Standardized biofilm" corresponds to the average value of 3 replicates; the "error bar" represents standard deviation of 3 replicates; ${ }^{* *} P<0.01$; ${ }^{* \star *} P<0.001$; the "N.C" (negative control) refers to the strains cultured in $2216 \mathrm{E}$ broth without exogenous 3-oxo- $\mathrm{C}_{10}-\mathrm{HSL}$ for $36 \mathrm{~h}$. 
in the $40 \mu \mathrm{mol} / \mathrm{L} 3$-oxo- $\mathrm{C}_{10}$-HSL treated group, it formed a ridge-like and rougher biofilm with a significantly decreased matrix. Interestingly, in the $100 \mu \mathrm{mol} / \mathrm{L} 3$-oxo- $\mathrm{C}_{10}$-HSL treated group, no biofilms were formed and only few colonies were observed.

Biofilms were thin and microcolonies were absent in the negative control of strain $\mathrm{N}^{\circ} 24$. Compared to this, the biomass and roughness of the biofilms with added 10 and $20 \mu \mathrm{mol} / \mathrm{L}$ 3 -oxo- $\mathrm{C}_{10}$-HSL were significantly enhanced, but the average thickness of both groups remained thin $(5-7 \mu \mathrm{m})$ with several detected microcolonies. For strain $\mathrm{N}^{\circ} 40$, the biomass and maximum thickness of the 40 and $100 \mu \mathrm{mol} / \mathrm{L} 3$-oxo- $\mathrm{C}_{10}$-HSL treated groups decreased significantly compared to the negative controls, where microcolony counts decreased especially in the $100 \mu \mathrm{mol} / \mathrm{L} 3$-oxo- $\mathrm{C}_{10}$-HSL but its roughness was enhanced at the same time (Table 3 ).

\section{Effects of 3-oxo-C $10-\mathrm{HSL}$ on Biofilm Formation at $28^{\circ} \mathrm{C}$}

Addition of 3-oxo- $\mathrm{C}_{10}$-HSL also affected the formation of biofilms as shown in Figure 6A. For example, the biofilms of strain $\mathrm{N}^{\circ} 24$ significantly decreased in $1 \mu \mathrm{mol} / \mathrm{L}$ treated group but became significantly higher in treatments added with 10 and 20 $\mu \mathrm{mol} / \mathrm{L}$. In contrast, biofilm formation in strain $\mathrm{N}^{\circ} 40$ was only increased in $1 \mu \mathrm{mol} / \mathrm{L} 3$-oxo- $\mathrm{C}_{10}$-HSL treated group.

Strain $\mathrm{N}^{\circ} 24$ in the negative control group had pinpointlike biofilm structure with no bacterial colonies (Figure 6B). However, sparse biofilms with adhered bacterial cells were detected in $10 \mu \mathrm{mol} / \mathrm{L} 3$-oxo- $\mathrm{C}_{10}$ - $\mathrm{HSL}$ treated group, and scattered biofilms with small colonies were also detected in 20 $\mu \mathrm{mol} / \mathrm{L} 3$-oxo- $\mathrm{C}_{10}$-HSL treated group. Meanwhile, strain $\mathrm{N}^{\circ} 40$ in the negative control group formed a solid biofilm matrix with approximately $100 \%$ substratum coverage (Figure 6C). In $1 \mu \mathrm{mol} / \mathrm{L} 3$-oxo- $\mathrm{C}_{10}$-HSL treated group, thicker biofilms with multiple layers of bacterial cells adhered to the matrix were observed.

For strain $\mathrm{N}^{\circ} 24$, the biomass and roughness of the 10 and $20 \mu \mathrm{mol} / \mathrm{L} 3$-oxo- $\mathrm{C}_{10}$-HSL treated groups were significantly enhanced compared to the negative control group. Its thickness also increased when added with $10 \mu \mathrm{mol} / \mathrm{L}$ of 3 -oxo- $\mathrm{C}_{10}-\mathrm{HSL}$ but more microcolonies formed after addition of $20 \mu \mathrm{mol} / \mathrm{L}$. For strain $\mathrm{N}^{\circ} 40$, the roughness of the $1 \mu \mathrm{mol} / \mathrm{L} 3$-oxo- $\mathrm{C}_{10}$-HSL treated group were the same as those in the negative control group, while the biomass and average thickness increased with more microcolonies (Table 4).

\section{DISCUSSION}

\section{AHL Profiles of $V$. alginolyticus}

As essential components of QS systems, AHLs have been detected in many Vibrio species, including $V$. sinaloensis, $V$. brasiliensis, $V$. ichthyoenteri, V. vulnificus, V. scophthalmi, V. anguillarum (Buchholtz et al., 2006; Garcia-Aljaro et al., 2008; Valiente et al., 2009; Li et al., 2010; Tan P. W. et al., 2014; Tan W. S. et al., 2014). However, to date, no systematic study of AHL distribution in $V$. alginolyticus are available, which hinders further understanding on the mechanisms underlying $V$. alginolyticus infection controls associated with QS system. Thus, the first step in our study was to classify and identify the wide range of AHLs produced by the $V$. alginolyticus isolates.

In this study, the negative results seen in C. violaceum CV026 detection suggest that the short side-chain AHLs might not be produced in $V$. alginolyticus, or that the AHL concentrations were below the detectable limit, consistent with those reported by Nievas et al. (2012) using the same detection assay. In contrast, the positive detection in A. tumefaciens KYC55 indicated that most tested $V$. alginolyticus strains could produce various AHLs $\left(\mathrm{C}_{4}\right.$-HSL $\sim \mathrm{C}_{14}$-HSL), most of which could be long side-chain AHLs ( $\mathrm{C}_{8}$-HSL $\sim \mathrm{C}_{14}$-HSL) with varying level of AHL production among strains. The HPLC-MS/MS we used to quantify the AHLs provided more detailed information on their production (Purohit et al., 2013). Out of the 14 target AHLs, our results confirmed 11 kinds of AHLs existing in $V$. alginolyticus, including both short and long side-chains, mainly dominated by $3-\mathrm{OH}-\mathrm{C}_{4}$-HSL, 3-oxo- $\mathrm{C}_{10}$-HSL, and 3-oxo- $\mathrm{C}_{14}$-HSL. Despite the exhaustive methods we used to profile the AHLs, the other types may also be produced by $V$. alginolyticus but not just detected in this study which warrants further studies and investigations.

Current studies reported a wide range of AHLs produced by Vibrio including $\mathrm{C}_{4}$ - $\mathrm{HSL}, 3-\mathrm{OH}-\mathrm{C}_{4}-\mathrm{HSL}, \mathrm{C}_{6}-\mathrm{HSL}$, 3-oxo$\mathrm{C}_{6}-\mathrm{HSL}, 3-\mathrm{OH}-\mathrm{C}_{6}-\mathrm{HSL}, \mathrm{C}_{8}-\mathrm{HSL}, 3-\mathrm{OH}-\mathrm{C}_{8}-\mathrm{HSL}, \mathrm{C}_{10}-\mathrm{HSL}, 3-$ $\mathrm{OH}-\mathrm{C}_{10}$-HSL, 3-oxo- $\mathrm{C}_{10}$-HSL, 3-OH-C 12 -HSL, 3-oxo- $\mathrm{C}_{12}$-HSL (Buchholtz et al., 2006; Garcia-Aljaro et al., 2008; Valiente

TABLE 3 | Quantitative analysis of the biofilm matrices of $V$. alginolyticus strains at $16^{\circ} \mathrm{C}$.

\begin{tabular}{|c|c|c|c|c|c|c|}
\hline \multicolumn{2}{|c|}{ Strains and culture conditions } & \multirow{2}{*}{$\begin{array}{c}\text { BioMass }\left(\mathbf{m g} / \mathrm{cm}^{3}\right) \\
0.550 \pm 0.072\end{array}$} & \multirow{2}{*}{$\begin{array}{c}\text { Average thickness }(\mu \mathrm{m}) \\
5.106 \pm 1.103\end{array}$} & \multirow{2}{*}{$\begin{array}{c}\text { Max thickness }(\boldsymbol{\mu m}) \\
10.000 \pm 4.243\end{array}$} & \multirow{2}{*}{$\begin{array}{c}\begin{array}{c}\text { Roughness } \\
\text { coefficient }\end{array} \\
0.910 \pm 0.090\end{array}$} & \multirow{2}{*}{$\begin{array}{c}\begin{array}{c}\text { Microcolonies at } \\
\text { substrate }\end{array} \\
\text { ND }\end{array}$} \\
\hline N 24 & N.C & & & & & \\
\hline & $10 \mu \mathrm{mol} / \mathrm{L}$ 3-oxo- $\mathrm{C}_{10}-\mathrm{HSL}$ & $1.652 \pm 1.198^{*}$ & $6.722 \pm 1.725$ & $17.000 \pm 4.243^{*}$ & $1.543 \pm 0.048^{*}$ & $2.500 \pm 2.121^{*}$ \\
\hline & $20 \mu \mathrm{mol} / \mathrm{L}$ 3-oxo- $\mathrm{C}_{10}-\mathrm{HSL}$ & $1.543 \pm 1.177^{\star}$ & $5.438 \pm 1.279$ & $13.000 \pm 1.414$ & $1.189 \pm 0.493^{*}$ & $1.500 \pm 2.121^{*}$ \\
\hline \multirow[t]{3}{*}{$N^{\circ} 40$} & N.C & $13.588 \pm 3.366$ & $10.475 \pm 3.763$ & $26.000 \pm 2.828$ & $0.318 \pm 0.060$ & $50.000 \pm 12.728$ \\
\hline & $40 \mu \mathrm{mol} / \mathrm{L}$ 3-oxo- $\mathrm{C}_{10}-\mathrm{HSL}$ & $3.627 \pm 0.408^{\star \star}$ & $6.558 \pm 1.190$ & $19.667 \pm 0.577^{\star}$ & $0.683 \pm 0.103$ & $39.667 \pm 3.215$ \\
\hline & $100 \mu \mathrm{mol} / \mathrm{L}$ 3-oxo- $\mathrm{C}_{10}-\mathrm{HSL}$ & $0.777 \pm 0.022^{\star \star}$ & $7.580 \pm 0.511$ & $18.500 \pm 2.121^{*}$ & $1.494 \pm 0.022^{*}$ & $1.000 \pm 0.000^{*}$ \\
\hline
\end{tabular}

Biofilm matrix index values were analyzed using COMSTAT software and shown as mean of 3 replicates with standard deviation. The "N.C" (negative control) refers to the strains cultured in 2216 E broth without exogenous 3-oxo-C $10-H S L$ for 36 ; the "ND" - not detected; ${ }^{*} P<0.05$; ${ }^{* *} P<0.01$. 


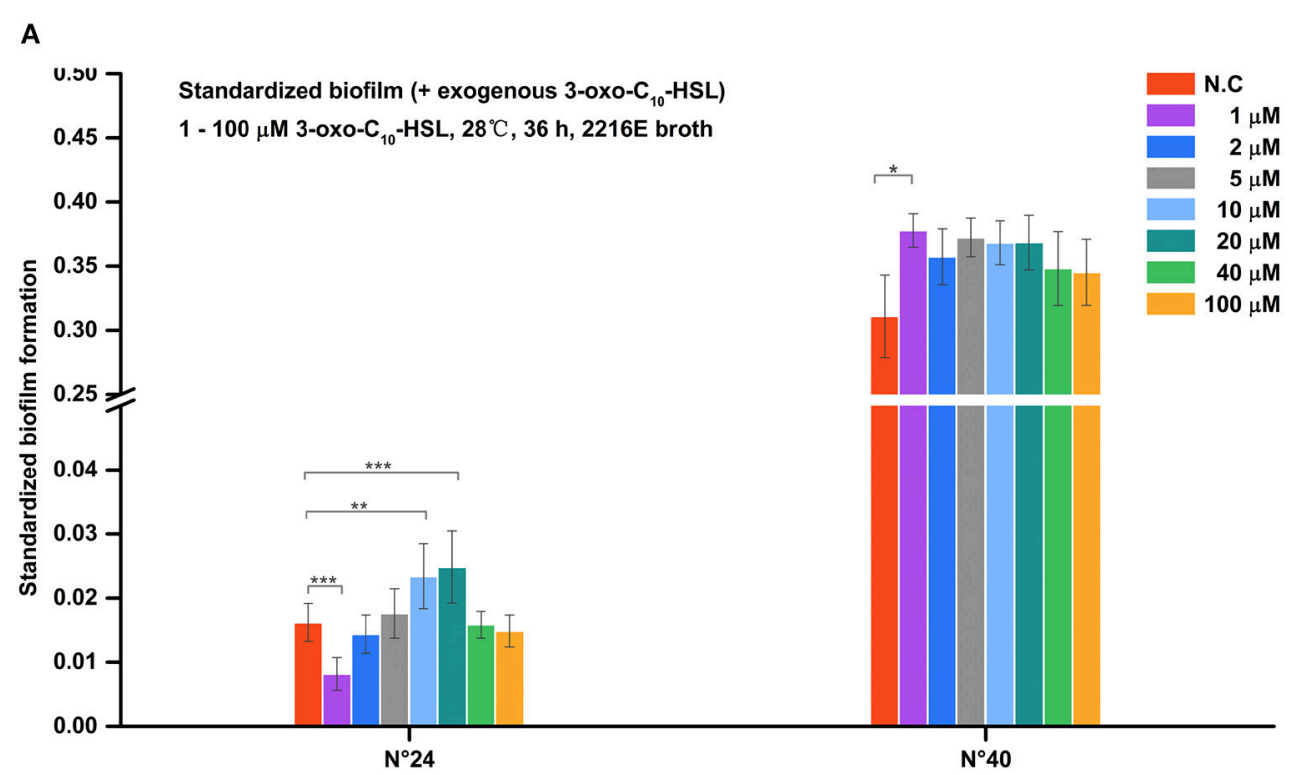

B

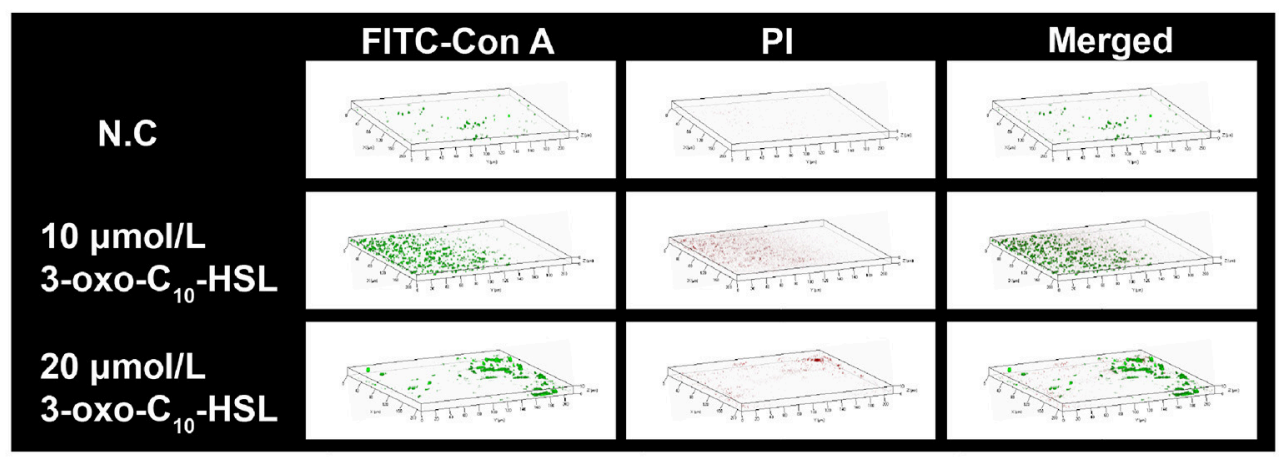

C

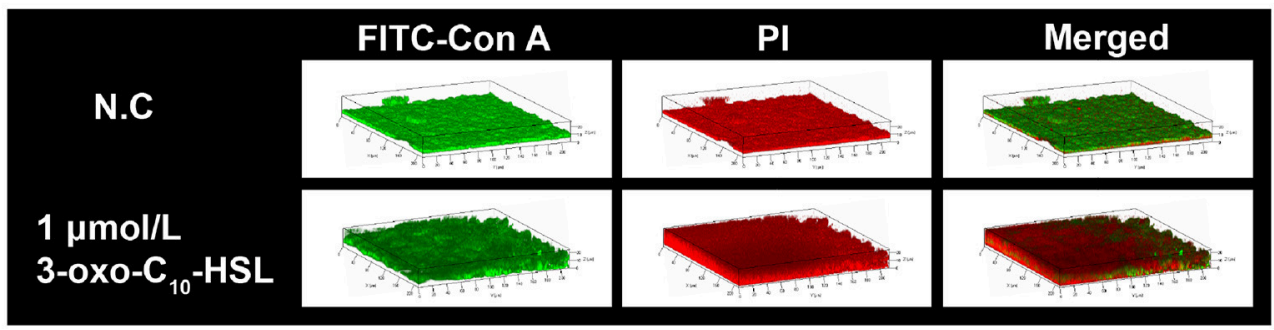

FIGURE 6 | Biofilm formation of $V$. alginolyticus supplemented with exogenous 3-oxo- $\mathrm{C}_{10}-\mathrm{HSL}$ at $28^{\circ} \mathrm{C}$ (A) Quantification of biofilm formed by strains $\mathrm{N}^{\circ} 24$ and $\mathrm{N}^{\circ} 40$ cultured for $36 \mathrm{~h}$ at $28^{\circ} \mathrm{C}$ using the semi-quantitative adhesion test. (B) Representative 3D-reconstructed biofilm structure of strain N 24 using CLSM. (C) Representative 3D-reconstructed biofilm structure of strain N 40 using CLSM. The "Standardized biofilm" corresponds to the average value of 3 replicates; the "error bar" represents standard deviation of 3 replicates; ${ }^{\star} P<0.05 ;{ }^{\star \star} P<0.01$; ${ }^{\star \star \star} P<0.001$; the "N.C" (negative control) refers to the strains cultured in $2216 \mathrm{E}$ broth without exogenous 3-oxo- $\mathrm{C}_{10}-\mathrm{HSL}$ for $36 \mathrm{~h}$.

et al., 2009; Li et al., 2010; Purohit et al., 2013; Tan P. W. et al., 2014; Tan W. S. et al., 2014). In addition to these AHLs, we report for the first time $\mathrm{C}_{12}$-HSL and 3-oxo- $\mathrm{C}_{14^{-}}$ HSL for the genus Vibrio, suggesting a greater diversity of AHLs in the genus and this research area is worthy of further exploration.

\section{Biofilm Formation of V. alginolyticus}

In our study, only $6.4 \% \mathrm{~V}$. alginolyticus isolates formed strong biofilms. Using similar biofilm detection method, our result was in contrast with the study of Snoussi et al. (2008), who found that $87.5 \%$ of their environmental $V$. alginolyticus isolates had strong biofilm forming abilities. This difference was most likely 
TABLE 4 | Quantitative analysis of the biofilm matrices of $V$. alginolyticus strains at $28^{\circ} \mathrm{C}$.

\begin{tabular}{|c|c|c|c|c|c|c|}
\hline \multicolumn{2}{|c|}{ Strains and culture conditions } & \multirow{2}{*}{$\begin{array}{c}\text { BioMass }\left(\mathbf{m g} / \mathrm{cm}^{3}\right) \\
0.046 \pm 0.024\end{array}$} & \multirow{2}{*}{$\begin{array}{c}\text { Average thickness }(\mu \mathrm{m}) \\
3.736 \pm 1.247\end{array}$} & \multirow{2}{*}{$\begin{array}{c}\text { Max thickness }(\mu \mathrm{m}) \\
8.500 \pm 2.121\end{array}$} & \multirow{2}{*}{$\begin{array}{c}\begin{array}{c}\text { Roughness } \\
\text { coefficient }\end{array} \\
0.491 \pm 0.358\end{array}$} & \multirow{2}{*}{$\begin{array}{c}\begin{array}{c}\text { Microcolonies at } \\
\text { substrate }\end{array} \\
2.500 \pm 0.707\end{array}$} \\
\hline$N^{\circ} 24$ & N.C & & & & & \\
\hline & $1 \mu \mathrm{mol} / \mathrm{L}$ 3-oxo-C $10-\mathrm{HSL}$ & ND & ND & ND & ND & ND \\
\hline & $10 \mu \mathrm{mol} / \mathrm{L} 3-\mathrm{OXO}-\mathrm{C}_{10}-\mathrm{HSL}$ & $2.949 \pm 0.086^{\star \star}$ & $6.090 \pm 2.083^{\star}$ & $9.000 \pm 1.414$ & $1.842 \pm 0.138^{\star \star}$ & $2.500 \pm 0.707$ \\
\hline & $20 \mu \mathrm{mol} / \mathrm{L}$ 3-oxo-C $10-\mathrm{HSL}$ & $3.273 \pm 0.127^{\star \star}$ & $4.090 \pm 0.628$ & $11.000 \pm 1.414$ & $1.297 \pm 0.646^{\star \star}$ & $6.000 \pm 1.414$ \\
\hline \multirow[t]{2}{*}{$N^{\circ} 40$} & N.C & $9.984 \pm 1.677$ & $12.987 \pm 2.124$ & $21.000 \pm 2.646$ & $0.187 \pm 0.025$ & $36.733 \pm 4.162$ \\
\hline & $1 \mu \mathrm{mol} / \mathrm{L}$ 3-oxo-C $\mathrm{C}_{10}-\mathrm{HSL}$ & $15.167 \pm 2.262^{\star}$ & $17.808 \pm 2.556^{\star}$ & $21.500 \pm 2.364^{\star}$ & $0.234 \pm 0.074$ & $43.667 \pm 3.786$ \\
\hline
\end{tabular}

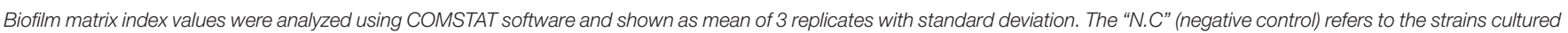
in 2216 E broth without exogenous 3-oxo-C $10-H S L$ for 36 h; the "ND" for not detected; ${ }^{*} P<0.05$; ${ }^{* *} P<0.01$.

attributed to the origin of the isolates, culture medium and temperature, and further implies that biofilm formation in $V$. alginolyticus is greatly influenced by environmental conditions.

Indeed, our results revealed that temperature affected $V$. alginolyticus biofilm formation. Stronger biofilms were formed at $16^{\circ} \mathrm{C}$ than at $28^{\circ} \mathrm{C}$, indicating higher biofilm biomass at relatively lower temperature. Studies on V. cholerae by Townsley and Yildiz (2015) also revealed a more compact biofilm matrix at lower temperature, consistent with our findings. In addition, biofilm structures became smoother with increasing temperature. Similar observations were reported by Remuzgo-Martinez et al. (2015). The rougher biofilms could provide larger surface area in favor of bacterial metabolism, while the smoother biofilms provide a stable environment to allow dormancy of bacterial cells (Donlan, 2002). Again, biofilm formation was completely inhibited at higher temperature $\left(40^{\circ} \mathrm{C}\right)$, even though $V$. alginolyticus strains were still growing. This response was also found in the biofilm formation of other bacteria such as Salmonella enteric (Piras et al., 2015). The inhibition of $V$. alginolyticus biofilm formation at high temperature could be associated with the degradation of the AHLs involved in biofilm formation, resulting to the total inhibition of production of AHL-controlled EPS (Yates et al., 2002).

\section{Exogenous 3-oxo- $\mathrm{C}_{10}$-HSL Affects Biofilm Formation in $\mathbf{V}$. alginolyticus}

Various physiological functions of long side-chain AHLs have been verified in many studies, such as biofilm formation (Nievas et al., 2012). Previous studies have confirmed that 3 -oxo- $\mathrm{C}_{10}-\mathrm{HSL}$ was highly correlated to bacterial pathogenicity, and that it could regulate several bacterial biological processes such as in activating expression of virulence-related genes (Buchholtz et al., 2006; Wang et al., 2013). It also participates in the red tide occurrences by causing the microalgae Ponticoccus sp. to aggregate and form massive blooms (Chi et al., 2017).

We found that exogenous 3-oxo- $\mathrm{C}_{10}$-HSL differently affected $V$. alginolyticus biofilm formation, with apparent strain specificity. For a strain that did not produce 3 -oxo- $\mathrm{C}_{10}-\mathrm{HSL}$ as that made weak biofilms, moderate concentration of 3-oxo$\mathrm{C}_{10}$-HSL promoted biofilm formation, and the corresponding morphological changes included increased cell auto-aggregation and biofilm heterogeneity. The morphological changes provided a suitable condition for the adhesion of bacterial cells to the biofilm surface, which was also observed before. For example, Huang et al. (2009) found that the dominant AHLs changed from short-chain to long-chain AHLs during subtidal biofilm development, and this change provided a heterogeneous environment in favor of more distinct bacterial community development and even for biofilm formation. The same effects were reported by Nievas et al. (2012), where moderate addition of 3-oxo- $\mathrm{C}_{10}$-HSL (10 or $20 \mu \mathrm{mol} / \mathrm{L}$ ) also increased biofilm formation of non-AHL-producing peanut-nodulating bacteria. For the strain with high level of 3-oxo- $\mathrm{C}_{10}$-HSL and strong biofilms, low concentration of 3 -oxo- $\mathrm{C}_{10}$-HSL still promoted biofilm formation but further addition inhibited the activity. Decreased cell auto-aggregation and biofilm integrity were associated with this inhibition. We presumed that in AHL-producing $V$. alginolyticus strains, both exogenous and endogenous 3-oxo- $\mathrm{C}_{10}$-HSL had possible cumulative effects on biofilm formation. This hypothesis however needs further validation and verification. In addition, the effects of exogenous 3-oxo- $\mathrm{C}_{10}$-HSL on the same $V$. alginolyticus strain varied under different temperature regimes, implying that 3 -oxo- $\mathrm{C}_{10}-\mathrm{HSL}$ effects could be influenced by changes in temperature.

\section{CONCLUSION}

Our study characterized 11 different AHLs produced by 47 $V$. alginolyticus strains, and further explored the production and the effect of AHLs on the regulation of $V$. alginolyticus biofilm formation. We confirmed the presence of AHLs, and the dominant kinds of AHL signals produced by the $47 \mathrm{~V}$. alginolyticus strains, and proposed a functional role of 3-oxo$\mathrm{C}_{10}$-HSL on biofilm formation. We also showed that temperature played an apparent role in regulating the said processes. Our results provide new insights for future studies.

\section{AUTHOR CONTRIBUTIONS}

KF and LZ conceptualized this study; JL, KF, YG, and LZ designed the research; JL, KF, YW, and CW conducted the experiments; JL, FL, and LS confirmed bacterial source and analyzed the data; JL and KF prepared the manuscript. JL and KF contributed equally to this work. All authors discussed the results, agreed 
on the interpretation and contributed in the finalization of the manuscript.

\section{FUNDING}

This work is supported by National Natural Science Foundation of China (Grant No.: 31400107 and 81273311).

\section{ACKNOWLEDGMENTS}

We thank Ms. Yanjun Li for providing the $V$. alginolyticus strains, Dr. Yigang Tong and his laboratory for the generous

\section{REFERENCES}

Abbas, A., Adams, C., Scully, N., Glennon, J., and O'Gara, F. (2007). A role for TonB1 in biofilm formation and quorum sensing in Pseudomonas aeruginosa. FEMS Microbiol. Lett. 274, 269-278. doi: 10.1111/j.1574-6968.2007.00845.x

Bassler, B. L. (1999). How bacteria talk to each other: regulation of gene expression by quorum sensing. Curr. Opin. Microbiol. 2, 582-587. doi: 10.1016/S1369-5274(99)00025-9

Buchholtz, C., Nielsen, K. F., Milton, D. L., Larsen, J. L., and Gram, L. (2006). Profiling of acylated homoserine lactones of Vibrio anguillarum in vitro and in vivo: influence of growth conditions and serotype. Syst. Appl. Microbiol. 29, 433-445. doi: 10.1016/j.syapm.2005.12.007

Caccamese, S. M., and Rastegar, D. A. (1999). Chronic diarrhea associated with Vibrio alginolyticus in an immunocompromised patient. Clin. Infect. Dis. 29, 946-947. doi: 10.1086/520473

Campos-Galvao, M. E., Ribon, A. O., Araujo, E. F., and Vanetti, M. C. (2016). Changes in the Salmonella enterica Enteritidis phenotypes in presence of acyl homoserine lactone quorum sensing signals. J. Basic Microbiol. 56, 493-501. doi: 10.1002/jobm.201500471

Cao, X., Wang, Q., Liu, Q., Rui, H., Liu, H., and Zhang, Y. (2011). Identification of a luxO-regulated extracellular protein Pep and its roles in motility in Vibrio alginolyticus. Microb. Pathog. 50, 123-131. doi: 10.1016/j.micpath.2010.1 2.003

Chang, C., Jing-Jing, Z., Chun-Hua, R., and Chao-Qun, H. (2010). Deletion of valR, a homolog of Vibrio harveyis luxR generates an intermediate colony phenotype between opaque/rugose and translucent/smooth in Vibrio alginolyticus. Biofouling 26, 595-601. doi: 10.1080/08927014.2010.499511

Chhabra, S. R., Stead, P., Bainton, N. J., Salmond, G. P., Stewart, G. S., Williams, P., et al. (1993). Autoregulation of carbapenem biosynthesis in Erwinia carotovora by analogues of N-(3-oxohexanoyl)-L-homoserine lactone. J. Antibiot. 46, 441-454. doi: 10.7164/antibiotics.46.441

Chi, W., Zheng, L., He, C., Han, B., Zheng, M., Gao, W., et al. (2017). Quorum sensing of microalgae associated marine Ponticoccus sp. PD-2 and its algicidal function regulation. AMB Express 7:59. doi: 10.1186/s13568-017-0357-6

Davis, B. M., Jensen, R., Williams, P., and O'Shea, P. (2010). The interaction of $\mathrm{N}$-acylhomoserine lactone quorum sensing signaling molecules with biological membranes: implications for inter-kingdom signaling. PLOS ONE 5:e13522. doi: 10.1371/journal.pone.0013522

De Oliveira, D. C., Fernandes Junior, A., Kaneno, R., Silva, M. G., Araujo Junior, J. P., Silva, N. C., et al. (2014). Ability of Salmonella spp. to produce biofilm is dependent on temperature and surface material. Foodborne Pathog. Dis. 11, 478-483. doi: 10.1089/fpd.2013.1710

Derlon, N., Peter-Varbanets, M., and Pronk, W. (2010). "Heterogeneous biofilms can help to stabilize long-term flux in gravity-driven deadend ultrafiltration systems: how protozoan grazing in fluences biofilm structure," in Proceedings of Biofilm Reactor Technology Conference (Portland, OR).

Donlan, R. M. (2002). Biofilms: microbial life on surfaces. Emerging Infect. Dis. 8, 881-890. doi: 10.3201/eid0809.020063

Eberhard, A., Burlingame, A. L., Eberhard, C., Kenyon, G. L., Nealson, K. H., and Oppenheimer, N. J. (1981). Structural identification of autoinducer gift of biosensor strain C. violaceum CV026 and for the help in its preparation. We thank Dr. Jun Zhu and his laboratory for generously providing us with the biosensor strain A. tumefaciens KYC55, and lastly, Dr. Hui Wang for her great help in the preparation and culturing of the biosensor strains.

\section{SUPPLEMENTARY MATERIAL}

The Supplementary Material for this article can be found online at: http://journal.frontiersin.org/article/10.3389/fmicb. 2017.01097/full\#supplementary-material

of Photobacterium fischeri luciferase. Biochemistry 20, 2444-2449. doi: 10.1021/bi00512a013

El-Sayed, A. K., Hothersall, J., and Thomas, C. M. (2001). Quorum-sensingdependent regulation of biosynthesis of the polyketide antibiotic mupirocin in Pseudomonas fluorescens NCIMB 10586. Microbiology 147, 2127-2139. doi: 10.1099/00221287-147-8-2127

Emerenini, B. O., Hense, B. A., Kuttler, C., and Eberl, H. J. (2015). A mathematical model of quorum sensing induced biofilm detachment. PLoS ONE 10:e132385. doi: 10.1371/journal.pone.0132385

Garcia-Aljaro, C., Eberl, L., Riedel, K., and Blanch, A. R. (2008). Detection of quorum-sensing-related molecules in Vibrio scophthalmi. BMC Microbiol. 8:138. doi: 10.1186/1471-2180-8-138

Garcia-Aljaro, C., Melado-Rovira, S., Milton, D. L., and Blanch, A. R. (2012). Quorum-sensing regulates biofilm formation in Vibrio scophthalmi. BMC Microbiol. 12:287. doi: 10.1186/1471-2180-12-287

Gauzere, B. A., Chanareille, P., and Vandroux, D. (2016). Post nearly drowning Vibrio alginolyticus septicemia acquired in reunion (Indian Ocean). Bull. Soc. Pathol. Exot. 109, 151-154. doi: 10.1007/s13149-016-0505-2

Golberg, K., Eltzov, E., Shnit-Orland, M., Marks, R. S., and Kushmaro, A. (2011). Characterization of quorum sensing signals in coral-associated bacteria. Microb. Ecol. 61, 783-792. doi: 10.1007/s00248-011-9848-1

Han-Jen, R. E., Wai-Fong, Y., and Kok-Gan, C. (2013). Pandoraea sp. RB44, a novel quorum sensing soil bacterium. Sensors 13, 14121-14132. doi: $10.3390 /$ s131014121

Hare, P., Long, S., Robb, F. T., and Woods, D. R. (1981). Regulation of exoprotease production by temperature and oxygen in Vibrio alginolyticus. Arch. Microbiol. 130, 276-280. doi: 10.1007/BF00425940

Hawver, L. A., Giulietti, J. M., Baleja, J. D., and Ng, W. L. (2016). Quorum sensing coordinates cooperative expression of pyruvate metabolism genes to maintain a sustainable environment for population stability. MBio 7:e01863-16. doi: $10.1128 / \mathrm{mBio} .01863-16$

He, J., Liu, H., Yang, J., Dong, X., and Wu, C. (2016). Abundant members of Scavenger receptors family and their identification, characterization and expression against Vibrio alginolyticus infection in juvenile Larimichthys crocea. Fish Shellfish Immunol. 50, 297-309. doi: 10.1016/j.fsi.2016.02.009

Heydorn, A., Nielsen, A. T., Hentzer, M., Sternberg, C., Givskov, M., Ersboll, B. K., et al. (2000). Quantification of biofilm structures by the novel computer program COMSTAT. Microbiology 146(Pt 10), 2395-2407. doi: 10.1099/00221287-146-10-2395

Horng, Y. T., Deng, S. C., Daykin, M., Soo, P. C., Wei, J. R., Luh, K. T., et al. (2002). The LuxR family protein SpnR functions as a negative regulator of $\mathrm{N}$-acylhomoserine lactone-dependent quorum sensing in Serratia marcescens. Mol. Microbiol. 45, 1655-1671. doi: 10.1046/j.1365-2958.2002.03117.x

Huang, Y. L., Ki, J. S., Lee, O. O., and Qian, P. Y. (2009). Evidence for the dynamics of Acyl homoserine lactone and AHL-producing bacteria during subtidal biofilm formation. ISME J 3, 296-304. doi: 10.1038/ismej.2008.105

Jamuna, B. A., and Ravishankar, R. V. (2016). Effect of small chain N acyl homoserine lactone quorum sensing signals on biofilms of food-borne pathogens. J. Food Sci. Technol. 53, 3609-3614. doi: 10.1007/s13197-016-2 346-1 
Jatt, A. N., Tang, K., Liu, J., Zhang, Z., and Zhang, X. H. (2015). Quorum sensing in marine snow and its possible influence on production of extracellular hydrolytic enzymes in marine snow bacterium Pantoea ananatis B9. FEMS Microbiol. Ecol. 91, 1-13. doi: 10.1093/femsec/fiu030

Kang, C. H., Shin, Y., Jang, S., Jung, Y., and So, J. S. (2016). Antimicrobial susceptibility of Vibrio alginolyticus isolated from oyster in Korea. Environ. Sci. Pollut. Res. Int. 23, 21106-21112. doi: 10.1007/s11356-016-7426-2

Khajanchi, B. K., Sha, J., Kozlova, E. V., Erova, T. E., Suarez, G., Sierra, J. C., et al. (2009). N-acylhomoserine lactones involved in quorum sensing control the type VI secretion system, biofilm formation, protease production, and in vivo virulence in a clinical isolate of Aeromonas hydrophila. Microbiology 155, 3518-3531. doi: 10.1099/mic.0.031575-0

Kumari, A., Pasini, P., Deo, S. K., Flomenhoft, D., Shashidhar, H., and Daunert, S. (2006). Biosensing systems for the detection of bacterial quorum signaling molecules. Anal. Chem. 78, 7603-7609. doi: 10.1021/ac061421n

Lamas, A., Fernandez-No, I. C., Miranda, J. M., Vazquez, B., Cepeda, A., and Franco, C. M. (2016). Biofilm formation and morphotypes of Salmonella enterica subsp. arizonae differs from those of other Salmonella enterica subspecies in isolates from poultry houses. J. Food Prot. 79, 1127-1134. doi: 10.4315/0362-028X.JFP-15-568

Li, X., Han, Y., Yang, Q., and Zhang, X. H. (2010). Detection of quorum sensing signal molecules and mutation of luxS gene in Vibrio ichthyoenteri. Res. Microbiol. 161, 51-57. doi: 10.1016/j.resmic.2009.10.004

Liu, H., Wang, Q., Liu, Q., Cao, X., Shi, C., and Zhang, Y. (2011). Roles of $\mathrm{Hfq}$ in the stress adaptation and virulence in fish pathogen Vibrio alginolyticus and its potential application as a target for live attenuated vaccine. Appl. Microbiol. Biotechnol. 91, 353-364. doi: 10.1007/s00253-0113286-3

Lumjiaktase, P., Diggle, S. P., Loprasert, S., Tungpradabkul, S., Daykin, M., Camara, M., et al. (2006). Quorum sensing regulates dpsA and the oxidative stress response in Burkholderia pseudomallei. Microbiology 152, 3651-3659. doi: 10.1099/mic.0.29226-0

Luo, L.-M., Wu, L.-J., Xiao, Y.-L., Zhao, D., Chen, Z.-X., Kang, M., et al. (2015). Enhancing pili assembly and biofilm formation in Acinetobacter baumannii ATCC19606 using non-native acyl-homoserine lactones. BMC. Microbiol. 15:62. doi: 10.1186/s12866-015-0397-5

Mastroleo, F., Van Houdt, R., Atkinson, S., Mergeay, M., Hendrickx, L., Wattiez, R., et al. (2013). Modelled microgravity cultivation modulates $\mathrm{N}$-acylhomoserine lactone production in Rhodospirillum rubrum $\mathrm{S} 1 \mathrm{H}$ independently of cell density. Microbiology 159, 2456-2466. doi: 10.1099/mic.0.066415-0

Mattiuzzo, M., Bertani, I., Ferluga, S., Cabrio, L., Bigirimana, J., Guarnaccia, C., et al. (2011). The plant pathogen Pseudomonas fuscovaginae contains two conserved quorum sensing systems involved in virulence and negatively regulated by RsaL and the novel regulator RsaM. Environ. Microbiol. 13, 145-162. doi: 10.1111/j.1462-2920.2010.02316.x

McClean, K. H., Winson, M. K., Fish, L., Taylor, A., Chhabra, S. R., Camara, M., et al. (1997). Quorum sensing and Chromobacterium violaceum: exploitation of violacein production and inhibition for the detection of $\mathrm{N}$-acylhomoserine lactones. Microbiology 143(Pt 12), 3703-3711. doi: 10.1099/00221287-143-12-3703

McLafferty, F. W., and Turecek, F. (1993). Interpretation of Mass Spectra. Mill Valley, CA: Univ Science Books.

Mechri, B., Medhioub, A., Medhioub, M. N., and Aouni, M. (2013). Genotypic diversity, antimicrobial resistance and screening of Vibrio cholerae molecular virulence markers in Vibrio alginolyticus strains recovered from a Tunisian Ruditapes decussatus hatchery. Pol. J. Microbiol. 62, 263-272.

Miller, C. L., Romero, M., Karna, S. L., Chen, T., Heeb, S., and Leung, K. P. (2016). RsmW, Pseudomonas aeruginosa small non-coding RsmA-binding RNA upregulated in biofilm versus planktonic growth conditions. BMC Microbiol. 16:155. doi: 10.1186/s12866-016-0771-y

Mireille Aye, A., Bonnin-Jusserand, M., Brian-Jaisson, F., Ortalo-Magne, A., Culioli, G., Koffi Nevry, R., et al. (2015). Modulation of violacein production and phenotypes associated with biofilm by exogenous quorum sensing $\mathrm{N}$ acylhomoserine lactones in the marine bacterium Pseudoalteromonas ulvae TC14. Microbiology 161, 2039-2051. doi: 10.1099/mic.0.000147

Morohoshi, T., Yamaguchi, T., Xie, X., Wang, W. Z., Takeuchi, K., and Someya, N. (2017). Complete genome sequence of Pseudomonas chlororaphis subsp. aurantiaca reveals a triplicate quorum-sensing mechanism for regulation of phenazine production. Microbes Environ. 32, 47-53. doi: 10.1264/jsme2.ME16162

Narracci, M., Acquaviva, M. I., and Cavallo, R. A. (2014). Mar Piccolo of Taranto: vibrio biodiversity in ecotoxicology approach. Environ. Sci. Pollut. Res. Int. 21, 2378-2385. doi: 10.1007/s11356-013-2049-3

Naves, P., del Prado, G., Huelves, L., Gracia, M., Ruiz, V., Blanco, J., et al. (2008). Correlation between virulence factors and in vitro biofilm formation by Escherichia coli strains. Microb. Pathog. 45, 86-91. doi: 10.1016/j.micpath.2008.03.003

Nievas, F., Bogino, P., Sorroche, F., and Giordano, W. (2012). Detection, characterization, and biological effect of quorum-sensing signaling molecules in peanut-nodulating bradyrhizobia. Sensors 12, 2851-2873. doi: 10.3390/s120302851

O'Connor, G., Knecht, L. D., Salgado, N., Strobel, S., Pasini, P., and Daunert, S. (2015). Whole-cell biosensors as tools for the detection of quorum-sensing molecules: uses in diagnostics and the investigation of the quorum-sensing mechanism. Adv. Biochem. Eng. Biotechnol. 154, 181-200. doi: 10.1007/10_2015_337

Okutsu, N., Morohoshi, T., Xie, X., Kato, N., and Ikeda, T. (2015). Characterization of $\mathrm{N}$-Acylhomoserine lactones produced by bacteria isolated from industrial cooling water systems. Sensors 16:E44. doi: 10.3390/s16010044

Piras, F., Fois, F., Consolati, S. G., Mazza, R., and Mazzette, R. (2015). Influence of temperature, source, and serotype on biofilm formation of Salmonella enterica isolates from Pig Slaughterhouses. J. Food Prot. 78, 1875-1878. doi: 10.4315/0362-028X.JFP-15-085

Pumbwe, L., Skilbeck, C. A., and Wexler, H. M. (2008). Presence of quorumsensing systems associated with multidrug resistance and biofilm formation in Bacteroides fragilis. Microb. Ecol. 56, 412-419. doi: 10.1007/s00248-007-9 358-3

Purohit, A. A., Johansen, J. A., Hansen, H., Leiros, H. K., Kashulin, A., Karlsen, C., et al. (2013). Presence of acyl-homoserine lactones in 57 members of the Vibrionaceae family. J. Appl. Microbiol. 115, 835-847. doi: 10.1111/jam.12264

Ravn, L., Christensen, A. B., Molin, S., Givskov, M., and Gram, L. (2001). Methods for detecting acylated homoserine lactones produced by Gramnegative bacteria and their application in studies of AHL-production kinetics. J. Microbiol. Methods 44, 239-251. doi: 10.1016/S0167-7012(01)00217-2

Remuzgo-Martinez, S., Lazaro-Diez, M., Mayer, C., Aranzamendi-Zaldumbide, M., Padilla, D., Calvo, J., et al. (2015). Biofilm formation and quorum-sensingmolecule production by clinical isolates of Serratia liquefaciens. Appl. Environ. Microbiol. 81, 3306-3315. doi: 10.1128/AEM.00088-15

Reuter, K., Steinbach, A., and Helms, V. (2016). Interfering with bacterial quorum sensing. Perspect. Medicin. Chem. 8, 1-15. doi: 10.4137/PMC.S13209

Schenk, S. T., Hernandez-Reyes, C., Samans, B., Stein, E., Neumann, C., Schikora, M., et al. (2014). N-Acyl-homoserine lactone primes plants for cell wall reinforcement and induces resistance to bacterial pathogens via the Salicylic Acid/Oxylipin pathway. 26, 2708-2723. doi: 10.1105/tpc.114.126763

Sganga, G., Cozza, V., Spanu, T., Spada, P. L., and Fadda, G. (2009). Global climate change and wound care: case study of an off-season Vibrio alginolyticus infection in a healthy man. Ostomy Wound Manage. 55, 60-62.

Sharma, S. R., Shankar, K. M., Sathyanarayana, M. L., Sahoo, A. K., Patil, R., Narayanaswamy, H. D., et al. (2010). Evaluation of immune response and resistance to diseases in tiger shrimp, Penaeus monodon fed with biofilm of Vibrio alginolyticus. Fish Shellfish Immunol. 29, 724-732. doi: 10.1016/j.fsi.2010.07.016

Sheng, L., Lv, Y., Liu, Q., Wang, Q., and Zhang, Y. (2013). Connecting type VI secretion, quorum sensing, and c-di-GMP production in fish pathogen Vibrio alginolyticus through phosphatase PppA. Vet. Microbiol. 162, 652-662. doi: 10.1016/j.vetmic.2012.09.009

Singh, R. P., Baghel, R. S., Reddy, C. R., and Jha, B. (2015). Effect of quorum sensing signals produced by seaweed-associated bacteria on carpospore liberation from Gracilaria dura. Front. Plant Sci. 6:117. doi: 10.3389/fpls.2015.00117

Snoussi, M., Noumi, E., Cheriaa, J., Usai, D., Sechi, L. A., Zanetti, S., et al. (2008). Adhesive properties of environmental Vibrio alginolyticus strains to biotic and abiotic surfaces. New Microbiol. 31, 489-500.

Soto, S. M., Smithson, A., Martinez, J. A., Horcajada, J. P., Mensa, J., and Vila, J. (2007). Biofilm formation in uropathogenic Escherichia coli strains: relationship with prostatitis, urovirulence factors and antimicrobial resistance. J. Urol. 177, 365-368. doi: 10.1016/j.juro.2006.08.081 
Stepanovic, S., Vukovic, D., Dakic, I., Savic, B., and Svabic-Vlahovic, M. (2000). A modified microtiter-plate test for quantification of staphylococcal biofilm formation. J. Microbiol. Methods 40, 175-179. doi: 10.1016/S0167-7012(00)00122-6

Swift, S., Downie, J. A., Whitehead, N. A., Barnard, A. M., Salmond, G. P., and Williams, P. (2001). Quorum sensing as a population-density-dependent determinant of bacterial physiology. Adv. Microb. Physiol. 45, 199-270. doi: 10.1016/S0065-2911(01)45005-3

Tan, P. W., Tan, W. S., Yunos, N. Y., Mohamad, N. I., Adrian, T. G., Yin, W. F., et al. (2014). Short chain N-acyl homoserine lactone production in tropical marine Vibrio sinaloensis strain T47. Sensors 14, 12958-12967. doi: 10.3390/s140712958

Tan, W. S., Yunos, N. Y., Tan, P. W., Mohamad, N. I., Adrian, T. G., Yin, W. F., et al. (2014). Characterisation of a marine bacterium Vibrio brasiliensis T33 producing N-acyl homoserine lactone quorum sensing molecules. Sensors 14, 12104-12113. doi: 10.3390/s140712104

Tateda, K., Ishii, Y., Horikawa, M., Matsumoto, T., Miyairi, S., Pechere, J. C., et al. (2003). The Pseudomonas aeruginosa autoinducer N-3oxododecanoyl homoserine lactone accelerates apoptosis in macrophages and neutrophils. Infect. Immun. 71, 5785-5793. doi: 10.1128/IAI.71.10.5785-579 3.2003

Townsley, L., and Yildiz, F. H. (2015). Temperature affects c-di-GMP signalling and biofilm formation in Vibrio cholerae. Environ. Microbiol. 17, 4290-4305. doi: 10.1111/1462-2920.12799

Tseng, B. S., Majerczyk, C. D., Passos da Silva, D., Chandler, J. R., Greenberg, E. P., and Parsek, M. R. (2016). Quorum sensing influences Burkholderia thailandensis biofilm development and matrix production. J. Bacteriol. 198, 2643-2650. doi: 10.1128/JB.00047-16

Turner, J. W., Malayil, L., Guadagnoli, D., Cole, D., and Lipp, E. K. (2014). Detection of Vibrio parahaemolyticus, Vibrio vulnificus and Vibrio cholerae with respect to seasonal fluctuations in temperature and plankton abundance. Environ. Microbiol. 16, 1019-1028. doi: 10.1111/1462-2920.12246

Valiente, E., Bruhn, J. B., Nielsen, K. F., Larsen, J. L., Roig, F. J., Gram, L., et al. (2009). Vibrio vulnificus produces quorum sensing signals of the AHL-class. FEMS Microbiol. Ecol. 69, 16-26. doi: 10.1111/j.1574-6941.2009.00 691.x

Vikstrom, E., Bui, L., Konradsson, P., and Magnusson, K. E. (2009). The junctional integrity of epithelial cells is modulated by Pseudomonas aeruginosa quorum sensing molecule through phosphorylation-dependent mechanisms. Exp. Cell Res. 315, 313-326. doi: 10.1016/j.yexcr.2008.10.044

Vinoj, G., Vaseeharan, B., Thomas, S., Spiers, A. J., and Shanthi, S. (2014). Quorum-quenching activity of the AHL-lactonase from Bacillus licheniformis DAHB1 inhibits Vibrio biofilm formation in vitro and reduces shrimp intestinal colonisation and mortality. Mar. Biotechnol. 16, 707-715. doi: 10.1007/s10126-014-9585-9
Vorregaard, M. (2008). Comstat2 - a Modern 3D Image Analysis Environment for Biofilms, in Informatics and Mathematical Modelling. Kongens Lyngby: Denmark Technical University of Denmark.

Wang, Y., Wang, H., Liang, W., Hay, A. J., Zhong, Z., Kan, B., et al. (2013). Quorum sensing regulatory cascades control Vibrio fluvialis pathogenesis. J. Bacteriol. 195, 3583-3589. doi: 10.1128/JB.00508-13

Williams, P., Winzer, K., Chan, W. C., and Camara, M. (2007). Look who's talking: communication and quorum sensing in the bacterial world. Philos. Trans. R. Soc. Lond. B. Biol. Sci. 362, 1119-1134. doi: 10.1098/rstb.2007.2039

Wu, Y. S., Tseng, T. Y., and Nan, F. H. (2016). Beta-1,3-1,6-glucan modulate the non-specific immune response to enhance the survival in the Vibrio alginolyticus infection of Taiwan abalone (Haliotis diversicolor supertexta). Fish Shellfish Immunol. 54, 556-563. doi: 10.1016/j.fsi.2016.04.127

Yang, K., Meng, J., Huang, Y. C., Ye, L. H., Li, G. J., Huang, J., et al. (2014). The role of the QseC quorum-sensing sensor kinase in epinephrine-enhanced motility and biofilm formation by Escherichia coli. Cell Biochem. Biophys. 70, 391-398. doi: 10.1007/s12013-014-9924-5

Yates, E. A., Philipp, B., Buckley, C., Atkinson, S., Chhabra, S. R., Sockett, R. E., et al. (2002). N-acylhomoserine lactones undergo lactonolysis in a pH-, temperature-, and acyl chain length-dependent manner during growth of Yersinia pseudotuberculosis and Pseudomonas aeruginosa. Infect. Immun. 70, 5635-5646. doi: 10.1128/IAI.70.10.5635-5646.2002

Zhang, C., Zhu, S., Jatt, A. N., and Zeng, M. (2016). Characterization of Nacyl homoserine lactones (AHLs) producing bacteria isolated from vacuumpackaged refrigerated turbot (Scophthalmus maximus) and possible influence of exogenous AHLs on bacterial phenotype. J. Gen. Appl. Microbiol. 62, 60-67. doi: 10.2323 /jgam. 62.60

Zhao, Q., Zhang, C., Jia, Z., Huang, Y., Li, H., and Song, S. (2014). Involvement of calmodulin in regulation of primary root elongation by $\mathrm{N}$-3-oxohexanoyl homoserine lactone in Arabidopsis thaliana. Front. Plant Sci. 5:807. doi: 10.3389/fpls.2014.00807

Zhu, J., and Mekalanos, J. J. (2003). Quorum sensing-dependent biofilms enhance colonization in Vibrio cholerae. Dev. Cell 5, 647-656. doi: 10.1016/S1534-5807(03)00295-8

Conflict of Interest Statement: The authors declare that the research was conducted in the absence of any commercial or financial relationships that could be construed as a potential conflict of interest.

Copyright (c) $2017 \mathrm{Liu}, \mathrm{Fu}, \mathrm{Wang}, \mathrm{Wu}, \mathrm{Li}$, Shi, Ge and Zhou. This is an open-access article distributed under the terms of the Creative Commons Attribution License (CC $B Y)$. The use, distribution or reproduction in other forums is permitted, provided the original author(s) or licensor are credited and that the original publication in this journal is cited, in accordance with accepted academic practice. No use, distribution or reproduction is permitted which does not comply with these terms. 